OPEN ACCESS

Edited by:

Jianlin Li,

Oak Ridge National Laboratory (DOE),

United States

Reviewed by:

Yutao Li,

The University of Texas at Austin,

United States

Dongwook Shin,

Hanyang University, South Korea

*Correspondence:

Zane A. Grady

zmg19@psu.edu

Specialty section:

This article was submitted to

Electrochemical Energy Conversion

and Storage,

a section of the journa

Frontiers in Energy Research

Received: 30 April 2020

Accepted: 10 August 2020

Published: 09 September 2020

Citation:

Grady ZA, Wilkinson CJ, Randall CA and Mauro JC (2020) Emerging Role of Non-crystalline Electrolytes in Solid-State Battery

Research. Front. Energy Res. 8:218.

doi: 10.3389/fenrg.2020.00218

\section{Emerging Role of Non-crystalline Electrolytes in Solid-State Battery Research}

\author{
Zane A. Grady ${ }^{1,2 *}$, Collin J. Wilkinson ${ }^{1,2}$, Clive A. Randall1,2 and John C. Mauro ${ }^{1,2}$ \\ ${ }^{1}$ Materials Research Institute, The Pennsylvania State University, University Park, PA, United States, ${ }^{2}$ Department of \\ Materials Science and Engineering, The Pennsylvania State University, University Park, PA, United States
}

As the need for new modalities of energy storage becomes increasingly important, allsolid-state secondary ion batteries seem poised to address a portion of tomorrow's energy needs. The success of such batteries is contingent on the solid-state electrolyte (SSE) meeting a set of material demands, including high bulk and interfacial ionic conductivity, processability with electrodes, electrode interfacial stability, thermal stability, etc. The demanding criteria for an ideal SSE has translated into decades of research devoted to discovering new electrolytes and modifying their structure/processing to improve their properties. While much research has focused on the electrolyte properties of polycrystalline ceramics, non-crystalline materials (glasses, amorphous solids, and partially crystallized materials) have demonstrated unique advantages in processability, stability, tunability, etc. These non-crystalline electrolytes are also fundamentally interesting for their potential contributions toward understanding ionic conduction in the solid state. In this review, we first review a decade of advances in two distinct families of non-crystalline lithium-ion electrolytes: lithium thiophosphate and lithium phosphate oxynitride. In doing so, we demonstrate two pathways for non-crystalline electrolytes to address the barriers toward development of all-solidstate batteries, viz., interfacial stability and conduction. Finally, we conclude with some discussion of the development of fundamental models of ionic conduction in the non-crystalline state, including the ongoing debate between strong and weak electrolyte theories. Collectively, these discussions make a promising case for the role of non-crystalline electrolytes in the next generation of energy storage technology.

Keywords: electrolyte, glass, amorphous, battery, ionic conduction

\section{INTRODUCTION}

The positive societal and cultural impacts of lithium secondary ion batteries (SIBs) cannot be understated (Ramstrom, 2019). However, as the global energy demand grows, it is becoming increasingly apparent that incremental improvements to the current modes of energy generation and storage may not remain a sustainable pathway (Janek and Zeier, 2016). Presently, the materials research community is wholly engaged in enabling the necessary radical departure(s) from 
conventional SIB technology. The replacement of the ubiquitous liquid electrolyte in commercial SIB with a solid-state electrolyte (SSE), the new battery configuration being termed an "all-solidstate battery" (ASSB), represents one such paradigmatic shift in energy storage technology (Nie et al., 2018).

All-solid-state battery can deliver increased specific capacities, operating voltages, thermal stability, safety, and power density compared to liquid electrolyte SIBs (Dunn et al., 2011; Larcher and Tarascon, 2015). However, the replacement of a liquid electrolyte with a solid material is non-trivial; many recent reviews of ASSB progress describe these challenges in great detail (Kerman et al., 2017; Manthiram et al., 2017; Xu et al., 2017; Famprikis et al., 2019a; Nakamura et al., 2019; Pervez et al., 2019; Shoji et al., 2019). High ionic conductivity (ca. $10^{-4} \mathrm{~S} / \mathrm{cm}$ ) is usually the first material requisite, but the criterion also includes properties such as high stability and high conductivity at the electrode interfaces, as well as the ability to process the SSE within feasible conditions for commercialization. These problems have proved difficult to ameliorate in polycrystalline ceramics and polymers (Zheng et al., 2018).

Non-crystalline electrolytes (NCEs) may be able to meet this lofty, and often paradoxical, set of material demands. NCEs have been shown to have ionic conductivities in the regime of liquid electrolytes and have no resistive grain boundaries due to their isotropic non-periodic structure. Moreover, their unique processability enables high degrees of interfacial contact. Advances in glass science over the previous decades have engendered new interest into the fundamental and applied aspects of NCEs (Bunde et al., 1998; Dyre et al., 2009; Chandra et al., 2013; Eckert and Martins Rodrigues, 2017; Famprikis et al., 2019a; Shoji et al., 2019).

This article will review developments in the understanding and application of NCEs in ASSBs, with emphasis on literature published within the preceding decade (2010-2019). To illustrate the diversity of NCEs, two promising non-crystalline electrolyte compositional families were selected as the focus of this review: lithium thiophosphate $\left(x \mathrm{Li}_{2} \mathrm{~S}-(100-x) \mathrm{P}_{2} \mathrm{~S}_{5}\right.$, LPS) and lithium phosphate oxynitride $\left(\mathrm{Li}_{x} \mathrm{PO}_{y} \mathrm{~N}_{z}, \mathrm{LiPON}\right)$. LPS has been shown to have ambient ionic conductivities in the range of $10^{-3} \mathrm{~S} / \mathrm{cm}$ and thus may directly replace the liquid electrolyte in similar configurations to the incumbent SIB technology, However, persistent problems related to Li-penetration when LPS is contacted with metallic lithium anodes and related interfacial compatibility problems remain under active investigation. LiPON, on the other hand, shows lower ambient ionic conductivity (ca. $10^{-6} \mathrm{~S} / \mathrm{cm}$ ) but can be sputtered to deposit a thin film electrolyte and thus may play a pivotal role in ASSBs with reduced dimensions (so-called "microbatteries"). Additionally, LiPON has also demonstrated a remarkable resistance to Li-penetration, possibly owing to its low electronic conductivity (Han et al., 2019). The relationships between structure and conductivity, as well as proof-of-concept NCE-ASSBs, are reviewed for these two compositional families. The review concludes with some discussion of developments toward a theoretical interpretation of the mechanisms of ionic conduction in the non-crystalline state.

\section{BACKGROUND}

\section{Motivation for Solid Electrolytes}

The conventional Li-SIB is the foundation of portable energy storage and is remarkably simple in design. Figure $\mathbf{1}$ schematically illustrates a typical Li-SIB. For comparison, a schematic of an ASSB with an alkali metal anode is also shown. Electrodes are placed on either side of an electrolyte layer generating an electrochemical potential whose open circuit voltage $\left(V_{o c}\right)$ is given by the differential between the two electrodes.

$$
V_{o c}=\left(\mu_{a}-\mu_{c}\right) / e
$$

here $\mu_{a}\left(\mu_{c}\right)$ is the chemical potential of the anode (cathode), and $e$ is the fundamental unit of charge. This potential differential imposes the driving force for charge carrier motion and also dictates its theoretical magnitude (i.e., the potential when no current flows through the circuit). During discharge, the electrochemical cell responds to this voltage by the redistribution of charge toward an equilibrium state through the transference of electrons from the anode to the cathode. An electrically insulating (typically $\sigma_{\text {electron }}<10^{-12} \mathrm{~S} / \mathrm{cm}$ ) but ionically conducting (typically $\sigma_{\text {ion }}>10^{-4} \mathrm{~S} / \mathrm{cm}$ ) electrolyte permits only ionic diffusion, thus forcing the electrons to perform electrical work in an external circuit (shown in Figure 1). The actual discharge voltage $\left(V_{\text {diss }}\right)$ is reduced from $V_{o c}$ by internal cell polarization and internal resistance.

$$
V_{\text {diss }}=V_{o c}-I R_{s y s}
$$

Where $I$ is the electrical current, $R_{s y s}$ includes the polarizations and resistances from the current collectors, component interfaces, etc. A battery's performance is evaluated based on how much power it can provide for a given mass or volume per cycle (gravimetric and volumetric capacities respectively). The energy density $(E, \mathrm{~W} \cdot \mathrm{h} / \mathrm{kg}$ or $\mathrm{W} \cdot \mathrm{h} / \mathrm{l})$ upon discharge can thus be expressed as

$$
E=\frac{C_{c} \times C_{a}}{C_{c}+C_{a}} \times V_{\text {diss }}
$$

Where $C_{c}\left(C_{a}\right)$ is the specific capacity of the cathode (anode). Further, the retention of capacity over iterative cycling is quantified by the Coulombic efficiency $(\mathrm{CE})$, which is the percent of specific discharge $(\mathrm{A} \cdot \mathrm{h} / \mathrm{kg}$ or $\mathrm{A} \cdot \mathrm{h} / \mathrm{l})$ retained upon immediate subsequent charging. $\mathrm{CE}$ is always less than $100 \%$ for real SIBs due to irreversible losses in the generation of interfacial compounds or loss of active material through other means. The lifetime of a SIB is often defined as the number of cycles until the cell only demonstrates $80 \%$ of its initial capacity, so a cell which has a lifetime of 500 cycles must have a CE of at least $99.96 \%$ for each cycle (Goodenough, 1998; Goodenough and Park, 2013; Lin et al., 2018). The rate at which SIB can deliver its energy is often reported in terms of 'crate.' A c-rate of $1 \mathrm{C}$ refers to the current density $\left(\mathrm{mA} / \mathrm{cm}^{2}\right)$ delivered by the battery at which the cell would deliver its entire theoretical capacity in a time interval of $1 \mathrm{~h}$. Thus, the 'rate performance' of a battery refers to the changes in properties such as capacity retention (i.e., CE) and cell polarization when the current density is varied. 


\section{A}

\section{Current secondary ion batteries}

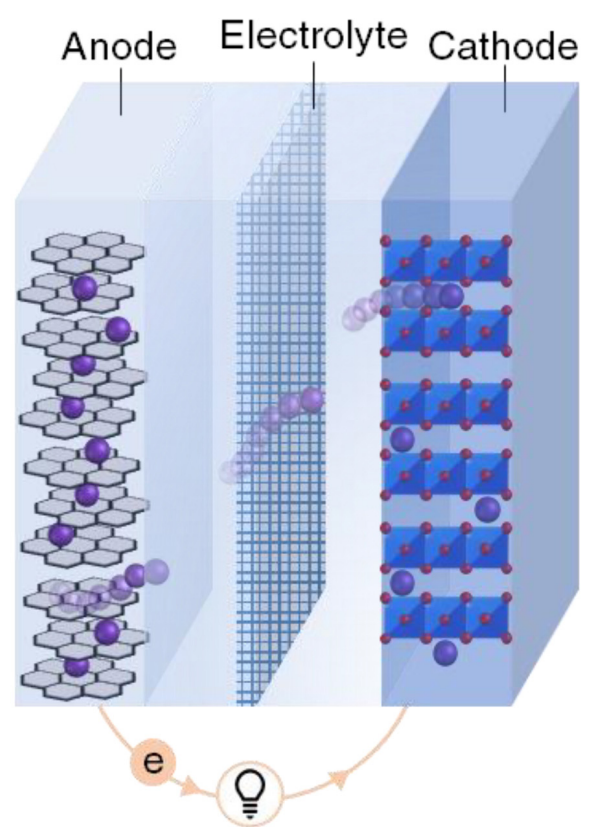

\section{B}

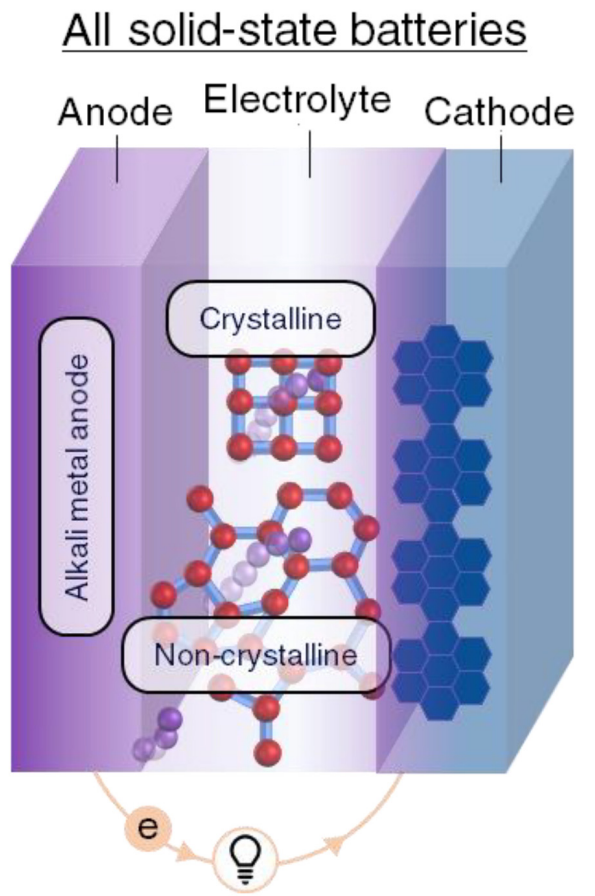

FIGURE 1 | Illustrations contrasting the current secondary ion battery technology (A) and an example of an all solid-state battery (B). The electrolyte is presumed to be a non-polymeric solid material in the all solid-state battery. Note the interfaces between components which play a key role in the performance of the cells.

The conventional Li-SIB utilizes a liquid electrolyte between the electrodes, whereas the proposed ASSBs instead employ a solid material as depicted in Figure 1. The ideal electrolyte has a high ionic conductivity $\left(\sigma_{\text {ion }}>10^{-3} \mathrm{~S} / \mathrm{cm}\right)$ and a negligible electronic conductivity $\left(\sigma_{\text {electron }}<10^{-12} \mathrm{~S} / \mathrm{cm}\right)$. Given the chemical potential differential between the electrodes, the ideal electrolyte thus forces the electrons to traverse the external circuit while allowing the ions to pass through the electrolyte between the electrodes. This process converts the chemical reaction energy into usable electrical energy as the system discharges toward a thermodynamically favorable state.

Thus, to summarize, the properties of the electrolyte impact cell performance in the following ways:

(1) Effective shuttling of ions: the ionic conductivity of the electrolyte must be sufficient (near $10^{-4} \mathrm{~S} / \mathrm{cm}$ ) to drive the necessary redox reactions and deliver current to the external circuit.

(2) Bounds of the chemical potential differential: the voltage imposed on the cell by the chemical potentials of the electrodes must be within the electrochemical stability window of the electrolyte. For liquids, the upper (lower) limit is given by the lowest unoccupied (highest occupied) molecular orbital. For solids, the upper (lower) limit is given by the conduction (valence) band energies, i.e., the magnitude and location of the band gap.

(3) Interfacial resistance with electrodes: one of the largest contributors to resistance in ASSBs, has been shown to be the resistive chemical/space charge boundary formed between non-liquid electrolytes and electrodes. SSEs can be modified to reduce this resistance.

(4) Resistance to decomposition during cycling: at the electrode electrolyte interface, passivating solid-electrolyte interphases (SEI) layers are often observed. These consume active material and increase resistance and should thus be minimized. This is intimately related to (3).

(5) For metallic anodes, preventing metal depositions which span the inter-electrode separation distance and short circuit the cell.

Other factors in battery operation include its operating temperature range, mechanical robustness, cost, environmental impact, etc. (Tarascon and Armand, 2001; Luntz et al., 2015; Kerman et al., 2017; Hou et al., 2018; Xu et al., 2018).

Non-aqueous electrolytes used in current Li-ion batteries are unable to completely satisfy these outlined criteria. Firstly, the operating potential window is limited to near $4 \mathrm{~V}$ versus the $\mathrm{Li} / \mathrm{Li}^{+}$, so without specifically tailored additives, the use of metallic lithium anodes results in the growth of high surface area lithium deposits and results in the catastrophic failure of the cell (Cheng et al., 2016). SSEs, by contrast, stand poised to address these concerns, having demonstrated $5 \mathrm{~V}$ stability windows, wide stability over a large thermal range (Inoue and Mukai, 2017), and a greatly increased resistance to lithium deposition (Tsai et al., 2016). 


\section{The Shortcomings of Solid Electrolytes}

A spectrum of SSEs have been discovered in the pursuit of materials which meet the demands described in the previous section. Their chemistries are varied, ranging from polycrystalline ceramics [e.g., $\mathrm{Na}_{3} \mathrm{Zr}_{2} \mathrm{Si}_{2} \mathrm{PO}_{12}$, $\mathrm{Li}_{1.3} \mathrm{Al}_{0.3} \mathrm{Ti}_{1.7}\left(\mathrm{PO}_{4}\right)_{3}, \quad \mathrm{Li}_{7} \mathrm{La}_{3} \mathrm{Zr}_{2} \mathrm{O}_{12}$ (Goodenough et al., 1976; Aono et al., 1990; Murugan et al., 2007)], polymers [e.g., Nafion (Aziz et al., 2018)], single crystals [e.g., LLZO (Kataoka et al., 2018)], glasses, glass-ceramics, and amorphous materials. The three types of electrolytes at the end of the list are the primary focus of this review. Numerous recent reviews have discussed the other types of electrolytes extensively (Kim et al., 2015; Gao et al., 2019). Figure 2 illustrates the range of conductivities as a function of temperature for representative crystalline, polymeric, liquid, amorphous, and glassy electrolytes.

Typically, a room temperature ionic conductivity of at least $10^{-4} \mathrm{~S} / \mathrm{cm}$ is required for a practical solid electrolyte (Zhang et al., 2018). The advent of "microbatteries" may utilize electrolytes with reduced thicknesses, such that a conductivity of $10^{-6} \mathrm{~S} / \mathrm{cm}$ is sufficient (Notten et al., 2007). Furthermore, one must consider the operating frequencies of the potential battery applications when evaluating conductivity of electrolytes which are often reported at much higher frequencies from impedance spectroscopy (Uddin and Cho, 2018).

It is apparent from Figure 2 that NCEs are not the only solid candidates to replace liquid electrolytes. Both polycrystalline and polymeric electrolytes demonstrate the minimum conductivity to be viable alternatives. However, fast ionic conduction through polycrystalline electrolytes is contingent on achieving high density, which often requires high temperature processing $\left(T_{\text {sinter }} \sim 2 / 3\right.$ of $\left.T_{m}\right)$. Such

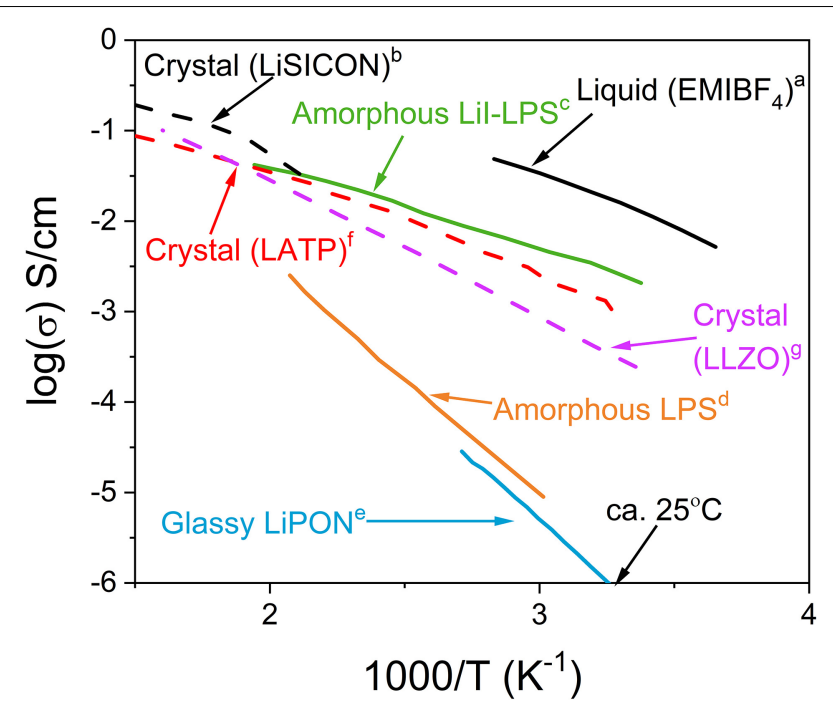

FIGURE 2 | Conductivity of representative liquid and crystalline electrolytes compared to pure LPS, LPS with Lil, and LiPON NCEs. Data taken from references (Saruwatari et al., 2010) ${ }^{a}$, (Hong, 1978) ${ }^{b}$, (Malugani and Robert, 1979) ${ }^{c}$, (Mizuno et al., 2006) ${ }^{d}$, (Nowak et al., 2015) $)^{e}$, (Aono et al., 1990) ${ }^{f}$, and (Murugan et al., 2007)g temperatures induce volatilization of the light alkali elements necessary for conduction and also typically precludes the possibility of co-processing with the electrodes (Von Alpen and Bell, 1981). On the other hand, polymeric electrolytes often demonstrate low intrinsic conductivities (ca. $10^{-8} \mathrm{~S} / \mathrm{cm}$ ) so they necessitate infiltration with some fraction of liquid electrolyte or the suspension of solid electrolyte particles (Aziz et al., 2018). The low elastic modulus and viscoelasticity of polymers allows for facile processing to form excellent interfacial contact with the electrodes but also decreases the ability of the polymer to stop the growth of lithium dendrites through the electrolyte (Keller et al., 2018). Polycrystalline electrolytes typically fair better against lithium penetration but lithium dendrite growth through the grain boundaries has been reported (Tsai et al., 2016).

\section{Non-crystalline Electrolytes}

In this review, we adopt the following definition of the glassy state, "a glass is a solid having a non-crystalline structure which continuously converts to a liquid on heating" (Varshneya and Mauro, 2019). This is shown graphically by comparing the volume-temperature relationships of liquids and glasses (Figure 3A). This definition is rooted in the unique thermodynamic and kinetic qualities of a non-equilibrium system whose structure is dictated by kinetic confinement (via loss of topological degrees of freedom) to a certain state in the potential energy landscape. This definition thus delineates an amorphous material from a glassy/vitreous one in the following way: an amorphous material (such as a non-crystalline material synthesized by mechanical milling below the melting temperature) continuously relaxes toward the crystalline state, whereas a glass (a non-crystalline material formed by the rapid cooling of a liquid structure) continuously relaxes toward the liquid state.

Given these explicit differences in amorphous and glassy materials, this review seeks to classify partially crystallized solids accordingly as either amorphous-ceramics or glass-ceramics in cases when the experimental details make such differences clear. While the term "glass-ceramic" has been heretofore applied broadly to all partially crystalline materials, the proposed disambiguation of "amorphous-ceramics" and "glass-ceramics" serves to respect the differences in the thermodynamic states of the respective matrix materials. Thus, this review seeks to use the applicable term when sufficient experimental detail is provided in the references. When an SSE is partially crystallized from a glassy state, it is labeled a glass-ceramic, whereas if the SSE was partially crystallized from an amorphous state it is labeled an amorphous-ceramic.

Appropriate categorization especially matters in the case of non-crystalline ionic conductors. Consider the internal relaxation time of a material as described by the Deborah number $\left(\Delta_{\text {num }}\right)$, which is defined as the ratio between the internal relaxation time of an ensemble $\left(\Delta_{\text {int }}\right)$ to the timescale of the observer $\left(\Delta_{o b s}\right)$, that is, $\Delta_{\text {num }}=\Delta_{\text {int }} / \Delta_{\text {obs }}$ (Wilkinson et al., 2019a). For gases, $\Delta_{\text {num }}<<1$, whereas for solids $\Delta_{\text {num }}>>1$ (Figure 3B). The glass transition may then be envisaged as a special case where $\Delta_{\text {num }} \sim 1$, such that the system 
A

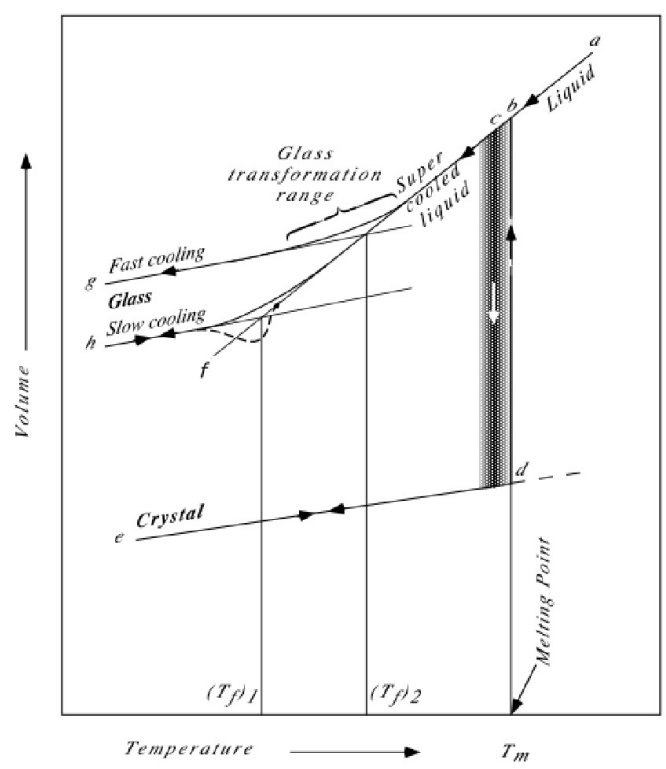

B

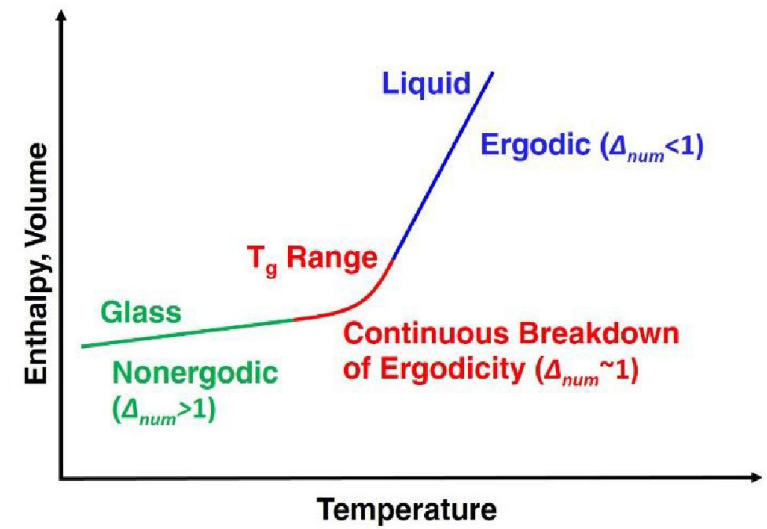

Temperature

FIGURE 3 | The changes in volume as a function of temperature for a liquid and glass, illustrating the relationship of the glass with its departure from equilibrium, reproduced from Varshneya and Mauro (2019) with permission, Copyright 2019 Elsevier (A). Regions of ergodicity, continuous breakdown of ergodicity, and non-ergodicity in the enthalpy or volume of a glass as a function of temperature (B).

continuously breaks ergodicity so the spatial ensemble average deviates from a unit ensemble average in the limit of infinite time (Mauro et al., 2009b).

Ionically conductive glasses are a special manifestation of these properties. Consider the simple expression for conductivity $(\sigma)$.

$$
\sigma=Z n e \mu
$$

where $Z$ is the unit charge integer, $n$ is the concentration of charge carriers, $\mu$ is the mobility of the charge carriers, and $e$ is fundamental unit of charge. Ideal electrolytes conduct only ions, not electrons, which can be quantitively expressed by the transference number $(\tau)$ where $\tau$ is the ratio of the mobile ions to the mobile electrons with respect to the total charge carriers such that $\tau$ approaches unity for ideal electrolytes. The mobility of such charge carriers is related to the diffusion coefficient $(D)$ by a factor of $\frac{e}{k_{b} T}$ where $k_{b}$ and $T$ are Boltzmann's constant and temperature, respectively. The Arrhenius scaling of $D$ with temperature is expressed as

$$
D=D_{o} \exp \left[-\left(\frac{Q}{k_{b} T}\right)\right]
$$

where the pre-exponential factor $\left(D_{o}\right)$ contains the vibrational frequency and jump distance, and $Q$ is the process activation energy (Hummel, 1985). Measurement of each quantity described in the preceding equations and their logical physical implications is often accomplished for liquid and ceramic materials. It is not straightforward in non-crystalline solids.

Ionic conduction in glassy SSEs has been and continues to be described by numerous authors employing numerous competing and, at times, contradictory theories (Dyre, 1986;
Dyre et al., 2009). Presently, the debate is largely focused on the question of whether glassy electrolytes behave as strong electrolytes $(\sigma=f(\mu(T)), n \neq f(T))$ (Anderson and Stuart, 1954; Tuller et al., 1980) or as weak electrolytes $(\sigma=f(n(T)), \mu \neq$ $f(T)$ ) (Ravaine and Souquet, 1977; Ingram et al., 1980; Ravaine, 1980). The debate is complicated by recalling the preceding discussion of internal timescales; does a diffusing ion have a different characteristic relaxation time than its rigid framework? If so, where does one define the "ergodic cutoff" (i.e., the relevant timescale) to define what constitutes a mobile charge carrier and which ions possess higher activation barriers for diffusion? Numerous authors have considered this question of ergodicity applied to an ionically conductive glass (Dyre et al., 2009; Balbuena et al., 2015). The obvious experimental solution is to quantify the conductivity over a dispersion of timescales (frequencies) through methods such as impedance spectroscopy; however, it behooves the reader to dwell on this notion because it emphasizes non-triviality of unambiguously ascribing thermodynamic models of conductivity to kinetically stabilized, non-equilibrium, phases of matter. In closing this review, a discussion of recent results in favor of the weak electrolyte theory is presented (Rodrigues et al., 2011; Welch et al., 2019; Wilkinson et al., 2020), but one must acknowledge that these notions may evolve in parallel with advances in the theory of the glassy state. Thus, while amorphous and glassy structures may appear functionally similar at laboratory time scales, admission of the underlying differences in thermodynamic and kinetic properties of the different states may be a precondition for the development of accurate models of ionic conduction in the non-crystalline states. 


\section{LITHIUM THIOPHOSPHATE (LPS)}

The family of $\mathrm{Li}_{2} \mathrm{~S}-\mathrm{P}_{2} \mathrm{~S}_{5}$ electrolytes is among the most studied of solid electrolyte systems. Within this family, there are crystalline, amorphous, glassy, and partially crystalline structures, examples of which are given in Table 1 along with their processing and properties. This review will focus on the non-crystalline members of the LPS family since the LPS system as a whole has been reviewed elsewhere (Berbano et al., 2013; Tatsumisago and Hayashi, 2014; Chen et al., 2018; Kudu et al., 2018).

\section{Structure-Property Relations in LPS}

Research pertaining to LPS can be traced back to the late 1970s, where Malugani, Mercier, and their respective collaborators identified high ionic conductivity when $\mathrm{Li}_{2} \mathrm{~S}-\mathrm{P}_{2} \mathrm{~S}_{5}$ glasses were doped with lithium halides (e.g., LiBr, LiI, LiI) (Malugani and Robert, 1979; Mercier et al., 1981). In the intervening decades, LPS has become a leading candidate in the race to replace the liquid electrolytes of conventional batteries. This section reviews the findings of recent investigations into the structure of LPS electrolytes and how subtle differences effect the bulk ionic conductivity and stability. In this section, the term amorphousceramic is used to describe partially crystalline materials which have been synthesized by mechanical milling while glass-ceramics is reserved for materials supercooled from the liquid state. This delineation respects the fundamental differences in the states of the matter, but it should be noted that the presence of mild glass-transition events has been reported for some amorphousceramics. Additional studies which decouple phase transitions of amorphous and glassy sulfide systems may shed light onto the similarities and differences in such non-crystalline materials.

Numerous recent investigations of the non-crystalline structure of LPS have been conducted (Auvergniot et al., 2017; Hakari et al., 2017; Koerver et al., 2018). Studies by Dietrich et al. (2017a,b, 2018) over the course of the previous decade have investigated the structure of LPS compounds across multiple length/time scales by using various methods of spectroscopy and scattering. In summary, their findings describe the bonding in the non-crystalline state from the perspective of sequential bond cleavages in the crystalline state. Thus, as a ceramic, LPS is characterized by four unique anionic species: $\mathrm{PS}_{4}^{3-}, \mathrm{P}_{2} \mathrm{~S}_{6}^{4-}$, $\mathrm{P}_{2} \mathrm{~S}_{7}^{4-}, \mathrm{P}_{2} \mathrm{~S}_{6}^{2-}$ (Figure 4A). In the glass or amorphous material, the authors propose a cleavage of bridging P-S-P bonds which, upon the presence of $\mathrm{Li}_{2} \mathrm{~S}$, yields a non-crystalline structure characterized by $\mathrm{PS}_{4}$ anionic building with a formal net negative charge of four electrons distributed equally across the entire unit. The negative charge is balanced by $\mathrm{Li}^{+}$counterions in the immediate vicinity. The ionic conductivity is found to increase as the predominant $\mathrm{P}_{x} \mathrm{~S}_{y}$ species transitions from di-tetrahedral $\mathrm{P}_{2} \mathrm{~S}_{7}^{4-}$ to $\mathrm{PS}_{4}^{3-}$ as the ratio of $\mathrm{Li}_{2} \mathrm{~S}_{2} \mathrm{P}_{2} \mathrm{~S}_{5}$ is varied, as shown in Figure 4B. Similarly, the activation energy is observed to decrease as the degree of non-bridging sulfur atoms is increased with increasing $\mathrm{Li}_{2} \mathrm{~S}$ content. The increase of conductivity associated with a decrease in the bonding strength is a recurring theme among NCEs, with more examples of this relationship being presented later in this review. The increase in activation energy and decrease in conductivity observed at the higher $\mathrm{Li}_{2} \mathrm{~S}: \mathrm{P}_{2} \mathrm{~S}_{5}$ ratios $(80: 20)$ is attributed to the formation of nonconducting $\mathrm{Li}_{2} \mathrm{~S}$ crystals (detected by XRD) in the amorphous material, resulting in a barrier to ionic diffusion. The authors also point out that the lack of a global trend in conductivity versus $\mathrm{Li}_{2} \mathrm{~S}$ content when comparing to similar literature may be related to the differing modes of sample preparation; Dietrich et al. (2017a) employ a mechanochemical technique while other authors use solution-based or melt quenching methods. The authors of this review hold a similar perspective; the method of synthesis probably affects the non-crystalline structure and thus conductivity. This viewpoint is shared by the authors of another recent review (Kudu et al., 2018) who present the properties of various LPS systems grouped by synthesis method. A systematic iso-compositional study of the properties and structure of LPS NCEs synthesized by various methods (such as from solution, mechanochemical, and melt quenching) is warranted.

Based on the previous results, the relationship between conductivity and structure in non-crystalline members of the LPS family should be interpreted from the perspective of the predominant P-S-P and lithium ion bonding energies and conformations. As shown in Figure 4B, the ionic conductivity

TABLE 1 | A compilation of some recent LPS compositions, their processing, and bulk conductivity at room temperature.

\begin{tabular}{|c|c|c|c|c|}
\hline Composition & Classification & Heat treatment $\left({ }^{\circ} \mathrm{C}\right)$ & $\sigma @ 25^{\circ} \mathrm{C}(\mathrm{S} / \mathrm{cm})$ & References \\
\hline $\mathrm{Li}_{3} \mathrm{PS}_{4}$ & Glass (wet chem.) & 200 & $1.64^{*} 10^{-4}$ & Liu et al., 2013 \\
\hline $90 \mathrm{Li}_{3} \mathrm{PS}_{4}-10 \mathrm{ZnO}$ & Amorphous-ceramic & 280 & $3.0^{\star} 10^{-4}$ & Hayashi et al., 2013 \\
\hline $9 \mathrm{Li}{ }_{2} S-3 P_{2} S_{5}-1 N_{3} S_{2}$ & Amorphous-ceramic & 260 & $2.0^{*} 10^{-3}$ & Park et al., 2017 \\
\hline $60 \mathrm{Li}_{2} \mathrm{~S}-25 \mathrm{P}_{2} \mathrm{~S}_{5}-10 \mathrm{Li} \mathrm{i}_{3} \mathrm{~N}$ & Amorphous-ceramic & 300 & $1.4^{\star} 10^{-3}$ & Fukushima et al., 2017 \\
\hline $70 \mathrm{Li}_{2} \mathrm{~S}-30 \mathrm{P}_{2} \mathrm{~S}_{5}$ & Glass-ceramic & 310 & $1.58^{*} 10^{-3}$ & Zhang et al., 2017 \\
\hline $80\left(0.7 \mathrm{Li}_{2} \mathrm{~S}-0.3 p 2 \mathrm{~S}_{5}\right)-20 \mathrm{Lil}$ & Amorphous & - & $5.6^{\star} 10^{-4}$ & Ujiie et al., 2012 \\
\hline $70 \mathrm{Li}_{2} \mathrm{~S}-30 \mathrm{P}_{2} \mathrm{~S}_{5}$ & Amorphous-ceramic & 300 & $3.1^{*} 10^{-3}$ & Seino et al., 2015 \\
\hline $99\left(70 \mathrm{Li}_{2} \mathrm{~S}-30 \mathrm{P}_{2} \mathrm{~S}_{5}\right)-1 \mathrm{Li}_{2} \mathrm{ZrO}_{3}$ & Amorphous-ceramic & 285 & $2.85^{\star} 10^{-3}$ & Lu et al., 2017 \\
\hline $70 \mathrm{Li}_{2} \mathrm{~S}-29 \mathrm{P}_{2} \mathrm{~S}_{5}-1 \mathrm{Li}_{3} \mathrm{PO}_{4}$ & Crystalline & 700 & $1.87^{*} 10^{-3}$ & Huang et al., 2015 \\
\hline $70 \mathrm{Li}_{2} \mathrm{~S}-30 \mathrm{P}_{2} \mathrm{~S}_{5}$ & Amorphous-ceramic & 270 & $8.4^{*} 10^{-4}$ & Aoki et al., 2017 \\
\hline 33Lil-67Li $\mathrm{PS}_{4}$ & Amorphous-ceramic & 180 & $6.50^{*} 10^{-3}$ & Spannenberger et al., 2019 \\
\hline $70 \mathrm{Li}_{2} \mathrm{~S}-30 \mathrm{P}_{2} \mathrm{~S}_{5}, 5 \mathrm{w}$ Kevlar & Amorphous-ceramic & 240 & $2.0^{*} 10^{-3}$ & Yersak et al., 2019 \\
\hline
\end{tabular}


A

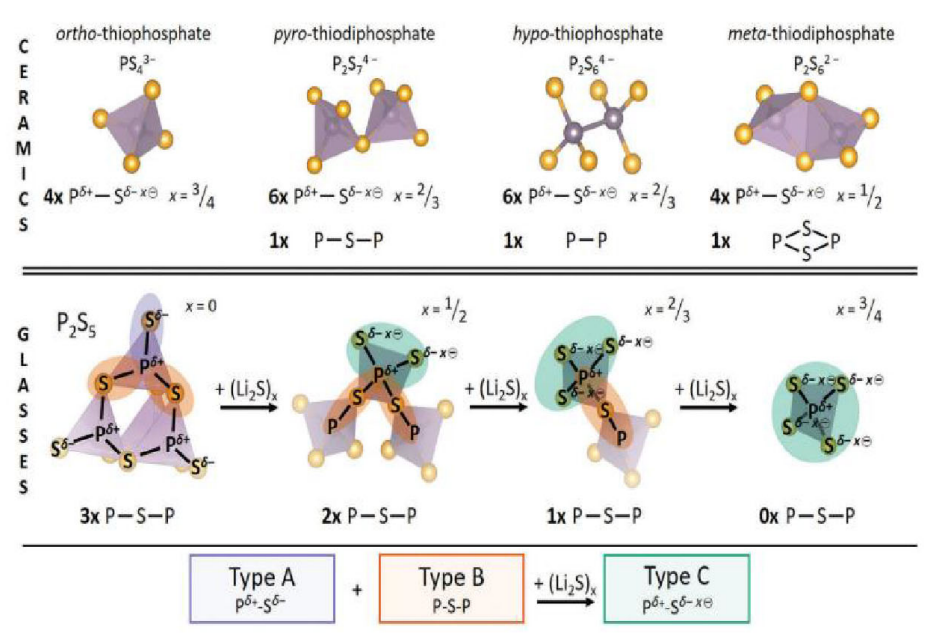

B

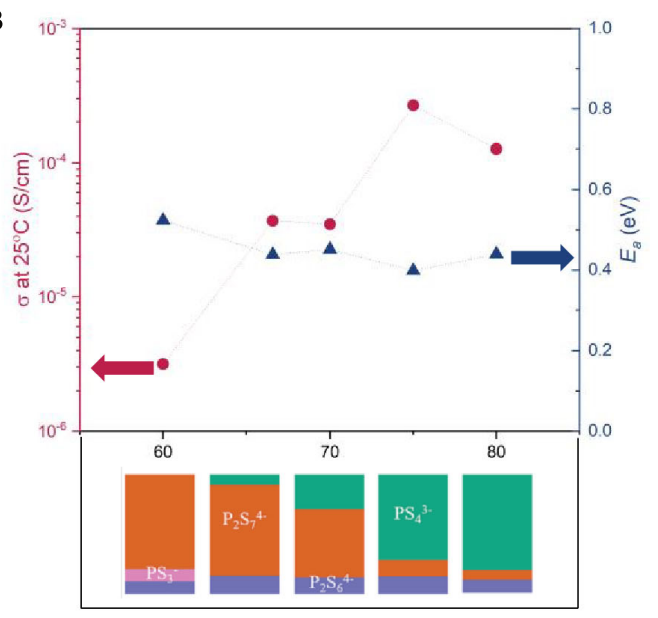

FIGURE 4 | (A) Proposed structural building blocks for the LPS system in the non-crystalline and crystalline state, based on XPS and neutron scattering data in Dietrich et al. (2018) and (B) the ionic conductivity as a function of the molar fraction $\mathrm{Li}_{2} \mathrm{~S}$, in addition to the corresponding activation energies and predominant $\mathrm{P}_{x} \mathrm{~S}_{\mathrm{y}}$ species. Data in (B) adapted from Dietrich et al. (2017b).

can increase by about two orders of magnitude when $x$ in $(100-\mathrm{x}) \mathrm{Li}_{2} \mathrm{~S}-(x) \mathrm{P}_{2} \mathrm{~S}_{5}$ is varied from 60 to 80 likely owing to the changes in bonding described above. Therefore, any study which seeks to draw correlations between the LPS composition and its conductivity must consider both the ratio of $\mathrm{Li}_{2} \mathrm{~S}$ and $\mathrm{P}_{2} \mathrm{~S}_{5}$, as well as the predominant bonding which can change as a function of processing.

Computational modeling of LPS structures confirms these experimental observations. Ohara et al. (2016) used a combination of computational (density functional theory, reverse Monte Carlo) and experimental techniques (Xray/neutron diffraction, Raman scattering) to build on this structure-composition-conductivity relationship. This work builds on previous experimentally derived correlations of LPS structure and conductivity, as described above, in addition to computational studies of the same (Onodera et al., 2012, 2013; Mori et al., 2013). An increase in $\mathrm{Li}_{2} \mathrm{~S}$ mole content from 67 to $75 \%$ (versus $\% \mathrm{P}_{2} \mathrm{~S}_{5}$ ) changes the predominant lithium species from $\mathrm{PS}_{4}$ and $\mathrm{P}_{2} \mathrm{~S}_{7}$ to mostly $\mathrm{PS}_{4}$ and some $\mathrm{P}_{2} \mathrm{~S}_{6}$ in such simulations. Simulations of the resulting structure showed that this was accompanied with an increase in edge sharing of the polyhedral, which was postulated to increase the interaction with the lithium ions in the structure to lower the conductivity. This is consistent with a plurality of the experimental measurements of different compositions of amorphous/glassy LPS as discussed previously. Furthermore, these computational results also shed light unto some of the mechanisms by which the change in polyanion oxidation and coordination contribute to the conductivity of the electrolyte. By calculating the density of states for a number of the polyanionic units identified in numerous independent structural studies, Ohara and coworkers were also able to show a change in the phosphorus polarization as a function of polyhedral coordination and presence of a LiI salt (Ohara et al., 2016).
The mechanisms underlying ionic conduction through noncrystalline LPS structures remain at least partially unresolved. However, it is clear that anion framework disorder plays a large role in the bulk conductivity, as well as the activation energies for site hopping (Heitmann et al., 2019). Similar relationships between the anionic arrangements surrounding mobile cations are well-documented in many crystalline solids with high ionic conductivities (Bachman et al., 2015), including the crystalline variants of LPS (Lau et al., 2018). It is therefore reasonable to conclude that certain anion-cation coordination (i.e., first coordination shells) favor fast ionic conduction, irrespective of the presence of long-range order. Thus, the differences between ionic conduction in LPS in crystalline and non-crystalline states are likely rooted in the intrinsic long-range disorder and metastability afforded by the non-equilibrium state of the noncrystalline electrolytes, a viewpoint which is supported by the following findings. Dietrich et al. (2018) showed that the lower P-S-P binding energy in the phosphate backbone favors ionic conduction through "depolymerization," concomitantly freeing lithium ions for conduction. Mori et al. (2013) conducted both computational and experimental studies of the energy required for lithium ions to site-hop in various LPS samples and used a bond valence mismatch approach (Adams and Rao, 2009) to conclude that certain LPS compositions conduct ions more favorably owing to a lower energy penalty for crossing coordination shell boundaries . Finally, Spannenberger et al. (2019) showed that the annealing of amorphous LPS electrolytes introduces "vacancies" in the non-crystalline structure which led to an increase in conductivity in the bulk. Strictly speaking, vacancies in non-crystalline materials differ from the crystalline analog due to the absence of well-defined and periodic locations in the former, but the essence of an empty site within an anionic framework which is energetically favorable for a cation is the same for both cases. Collectively, these are three 
representative examples which point to the metastability of LPS NCEs as a key factor in observed conductivities. The decreased energetic penalty for long-range ion site hopping, the increase in favorable empty cation sites, and simultaneous anionic framework rearrangement afforded by the kinetically stabilized (i.e., thermodynamically unstable) non-crystalline state are reconcilable with what is presently known about ionic conduction in the crystalline state, and thus may be a key part in explaining the fundamental ionic conduction mechanisms in LPS and other materials.

\section{Stability of LPS}

It is useful to regard electrolyte stability as containing 'intrinsic' and 'extrinsic' properties. In the case of NCEs, intrinsic stability refers to the stability of the non-crystalline phase relative to other thermodynamic phases such as crystalline phases of similar compositions or decomposition reactions with ambient atmosphere or elevated temperatures. Extrinsic stability, by contrast, can be used to refer to a materials' stability when interfaced electrode materials with varying chemical potentials. Generally, both facets of stability can be improved by structural tuning but sometimes at the expense of other properties, as will be shown in this section.

At the outset of this decade, it was reported that the LPS electrolytes undergo hydrolysis when exposed to humid atmosphere, resulting in the generation of $\mathrm{H}_{2} \mathrm{~S}$ gas by Muramatsu et al. (2011).

$$
\mathrm{Li}-\mathrm{S}-\mathrm{Li} \stackrel{\mathrm{H}_{2} \mathrm{O}}{\rightarrow} \mathrm{Li}-\mathrm{SH}+\mathrm{HO}-\mathrm{Li} \stackrel{\mathrm{H}_{2} \mathrm{O}}{\rightarrow} 2 \mathrm{LiOH}+\mathrm{H}_{2} \mathrm{~S}_{(\mathrm{g})}(4)
$$

The generation of such gasses necessitates that all processing and handling is carried out under inert environments, severely restricting the scale-up of ASSBs based on LPS NCEs. The stability of LPS can be improved by substituting oxygen on sulfur sites (Ohtomo et al., 2013a) but this has the effect of reducing the ionic conductivity to the $10^{-4} \mathrm{~S} / \mathrm{cm}$ range, rather than the higher $10^{-3} \mathrm{~S} / \mathrm{cm}$ range often observed for undoped LPS systems. This reduction in conductivity is likely related to the less polarizable oxyanions impeding the diffusion of lithium ion. This provides an example of the paradoxical nature of the criteria for ASSB
NCEs; a weakly bonded open structure is necessitated for fast ion conduction, but such structures are often inherently unstable with air or elevated temperatures. Examples of a reduction in $\mathrm{H}_{2} \mathrm{~S}$ from addition of minor mole fractions of $\mathrm{LiNbO}_{3}$ and the simultaneous changes in ionic conductivity are shown in Figures 5A,B, respectively (Ahmad et al., 2020).

In pursuit of a more stable LPS NCE which retains a conductivity above $10^{-3} \mathrm{~S} / \mathrm{cm}$, numerous researchers have explored combinations of doping LPS systems and partially crystallizing them into glass/amorphous-ceramics. The initial work on doping LPS with a network modifying salt was done by Malugani and Mercier with LiBr, LiC, LiI, etc. (Mercier et al., 1981). The conductivity of these samples was measured to be in the $10^{-3} \mathrm{~S} / \mathrm{cm}$ regime, which is similar to the state-of-the-art undoped LPS NCEs and one order of magnitude higher than what is usually reported for the non-salt doped glassy/amorphous LPS materials. These Li-salt doped NCEs also demonstrate stability at $100^{\circ} \mathrm{C}$ and high current densities (ca. $1.25 \mathrm{~mA} / \mathrm{cm}^{2}$ ) (Suyama et al., 2018). Subsequent recent investigations have examined the properties of the doped $\mathrm{Li}_{10+\delta} \mathrm{M}_{1+\delta} \mathrm{P}_{2-\delta} \mathrm{S}_{12}(\mathrm{M}=\mathrm{Si}$, Sn, Ge, P) glass and partially crystallized SSEs (Kamaya et al., 2011; Hori et al., 2014, 2016). Ge-doped samples can reach conductivities as high as $1.2 \times 10^{-3} \mathrm{~S} / \mathrm{cm}$, with the added benefit of decreased degradation when in contact with low potential anodes like metallic lithium. The other dopants ( $\mathrm{Sn}, \mathrm{Si}, \mathrm{P}$ ) give lower conductivities and it has been hypothesized that the Gesubstitution increases the volume of the lithium sites which enables faster diffusion, compared to the other dopant metals (Hori et al., 2014). A positive correlation between increases in the ionic diffusion pathway volume and values of ionic conductivity are well-documented for crystalline electrolytes as well (Bachman et al., 2015). The practical advantages of $\mathrm{Si}$ or $\mathrm{O}$ doping on the performance of LPS is shown in Figures 5C,D, where an increase in stability at high current density is observed when the electrolyte composition is changed from $0.6 \mathrm{Li}_{2} \mathrm{~S}+0.4 \mathrm{P}_{2} \mathrm{~S}_{5}$ to $0.6 \mathrm{Li}_{2} \mathrm{~S}+0.4\left[0.4 \mathrm{SiS}_{2}+0.9 \mathrm{P}_{2} \mathrm{~S}_{5}\right]$, respectively (Zhao et al., 2020).

Similar compositional modifications are effective in increasing LPS stability against metallic Li. The addition of $\mathrm{Li}_{2} \mathrm{O}$ to LPS can enable cycling with an Li anode (Ohtomo et al., 2013a,b,c).
A

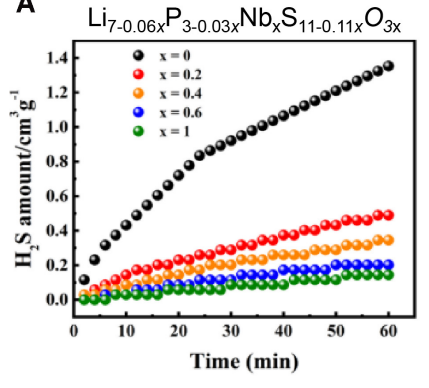

B

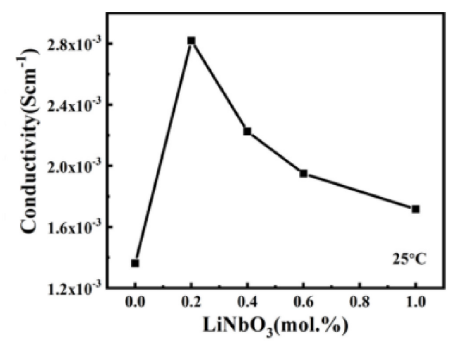

C

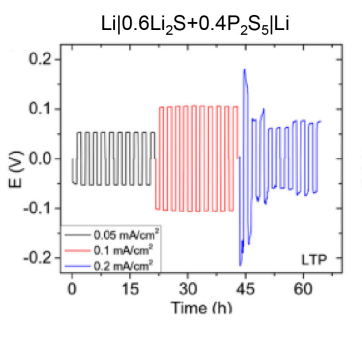

D

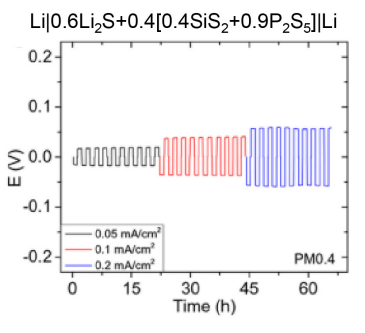

FIGURE 5 | Doping of LPS with $x \mathrm{LiNbO}_{3}$ reduces the amount of $\mathrm{H}_{2} \mathrm{~S}$ generated (A). The room temperature conductivity of the $\mathrm{Nb}$ doped LPS reaches a maximum for $0.2 \mathrm{~mol}_{\mathrm{L} \mathrm{LiNbO}_{3}}$ (B). A symmetric cell with an undoped LPS NCE shows electrical shorting at high current densities (C), while a symmetric cell with an $\mathrm{SiS}_{2}$-doped LPS NCE demonstrates enhanced stability at high current densities (D). (A,B) Reprinted (adapted) with permission from Ahmad et al. (2020). Copyright 2020 American Chemical Society. (C,D) Reprinted (adapted) with permission from Zhao et al. (2020). Copyright 2019 American Chemical Society. 
Other stability enhancing dopants include $\mathrm{LiBH}_{4}$ (Yamauchi et al., 2013), $\mathrm{Li}_{3} \mathrm{PO}_{4}$ (Mo et al., 2016), SiS 2 (Yersak et al., 2019), $\mathrm{P}_{2} \mathrm{~S}_{3}$ and $\mathrm{P}_{2} \mathrm{O}_{5}$ (Minami et al., 2011b); however, the conductivity is usually reduced to the $10^{-4} \mathrm{~S} / \mathrm{cm}$ regime. Excellent cyclability ( $>700$ cycles) and reversible capacity (ca. $140 \mathrm{~mA} \cdot \mathrm{h} / \mathrm{g}$ ) when LPS is doped with $\mathrm{P}_{2} \mathrm{O}_{5} / \mathrm{P}_{2} \mathrm{~S}_{3}$ (Minami et al., 2011a). The origin of such increased stability against reduction by Li likely lies in the increasing average bond strength of the doped NCEs.

While the increase in stability against reduction by $\mathrm{Li}$ is notable, the stability of LPS against metallic Li remains practically insufficient due to numerous decomposition reactions (Zhu et al., 2015). In addition to reduction driven a chemical potential gradient, the procession of Li 'dendrite' growth through dense LPS has been observed experimentally via neutron diffraction (Han et al., 2019). This study posits the increase electrical conductivity of non-crystalline LPS (ca. $10^{-8} \mathrm{~S} / \mathrm{cm}$ ) as the property of LPS which enables extended Li penetration. With this guidance, future investigations of LPS doping should rationally select dopants which reduce the bulk electrical conducivity, as opposed to previous efforts to solely increase the thermodynamic stability window.

Finally, the partial/total crystallization of LPS must be mentioned. Non-crystalline LPS can be exposed to heat and/or pressure to produce a gamut of crystalline variants. Among the possible crystalline forms, $\mathrm{Li}_{7} \mathrm{P}_{3} \mathrm{~S}_{11}$ (corresponding to a non-crystalline precursor of $70 \mathrm{Li}_{2} \mathrm{~S}: 30 \mathrm{P}_{2} \mathrm{~S}_{5}$ ) has been studied extensively due to its ease of synthesis and high ionic conductivity (ca. $10^{-3} \mathrm{~S} / \mathrm{cm}$ ) (Hayashi et al., 2008; Seino et al., 2015; Aoki et al., 2017). To illustrate the increase in conductivity during the crystallization process, Busche et al. (2016) have measured the in situ resistance (reciprocal of conductivity) of an initially completely non-crystalline LPS electrolyte during concurrent heating $\left(T_{\text {anneal }}=250^{\circ} \mathrm{C}\right)$ and uniaxial pressure $($ ca. $180 \mathrm{MPa})$. A decrease in resistance of about three orders of magnitude is observed during the crystallization process. The crystallization process must, however, be controlled such as to prevent the nucleation of less conductive phases (e.g., $\mathrm{Li}_{4} \mathrm{Si}_{2} \mathrm{P}_{6}$, and $\beta$ - $\mathrm{Li}_{3} \mathrm{PS}_{4}$ ) which yield lower conductivities (Hayashi et al., 2008; Seino et al., 2015; Aoki et al., 2017). Prolonged discussion of the various crystalline phases of LPS lies outside the scope of this review but the topic has been examined in detail in other recent reviews (Berbano et al., 2013; Ohtomo et al., 2013a; Chen et al., 2018; Kudu et al., 2018).

\section{LPS ASSB Demonstrations}

The culmination of the aforementioned studies investigating the conductivity and stability of LPS NCEs is the electrochemical cycling of secondary ion batteries employing such NCEs. In this section, the characterization of some of the electrode-electrolyte interfaces is described in practical demonstrations, concluding with collective the interpretation of a short collation of different electrode-electrolyte combinations and their resultant properties.

The matter of interfacial decomposition, previously addressed from a purely thermodynamic perspective, is further complicated by recent findings which demonstrate altered decomposition pathways due to the nature of the electrode and the act of cycling (Tsukasaki et al., 2018). In a direct comparison of ASSBs utilizing either an amorphous (75Li2S5:25P2S5) or a glass-ceramic (70Li2S5:30P2S5 heat treated to $290^{\circ} \mathrm{C}$ ) SSE, the ASSB with a glass electrolyte showed the better rate performance but suffered from an increased interfacial resistance after being held under open circuit conditions for extended periods of time, while the purely non-crystalline SSE showed better capacity retention (Ohtomo et al., 2013a). Since interfacial resistance is most often ascribed to the interfacial decomposition products, it follows that the difference in electrochemical performance is due to different decomposition pathways. Evidence for such altered decomposition pathways in ASSBs with LPS electrolytes is given in a study by Tsukasaki et al. (2018) which used in situ TEM to probe the evolution of an ASSB interface (LiNi1/3Mn1/3Co1/3O2 cathode, LPS electrolyte) during heating. In addition to one of the first direct observations of crystal nucleation within an amorphous structure, the authors also identified new decomposition pathways initiated by the insertion of excess $\mathrm{Li}^{+}$from the cathode. Such decomposition pathways might not be identified models which only consider the equilibrium chemical potential at the cathodic interface without accounting for a lithium reservoir. These two complementary examples demonstrate the potential complications which immediately arise when extending the system from solely the bulk SSE to a functioning electrochemical cell.

A representative selection of recent ASSB demonstrations that utilize an NCE based on LPS compositions is given in Table 2. For each battery, the electrolyte composition/classification, the working electrodes, operating voltage window, and the number of cycles with capacity retention of final cycle relative to initial cycle are given. Rather than endeavor to make an exhaustive list of LPSASSB reports, the table instead highlights the variety of electrodes used and their similarly varied performances. This allows for the ensuing discussion of the broader advantages and disadvantages of LPS as a solid electrolyte in ASSBs.

The ASSBs with LPS electrolytes summarized in Table 2 pursue numerous pathways toward enhanced electrochemical performance, including modification of the electrolyte composition, inclusion of numerous electrolytes, and selection of electrodes which are stable with LPS. First, it has been shown that varying the composition of pure LPS from $70 \mathrm{Li}_{2} \mathrm{~S}-30 \mathrm{P}_{2} \mathrm{~S}_{5}$ to $75 \mathrm{Li}_{2} \mathrm{~S}-25 \mathrm{P}_{2} \mathrm{~S}_{5}$ the stability can be increased at the expense of rate performance, respectively (Ohtomo et al., 2013c). This is consistent with the results reviewed in the previous section where certain LPS compositions demonstrate high stability while others provided higher ionic conductivity. The addition of $5 \mathrm{~mol} \% \mathrm{Li}_{3} \mathrm{PO}_{4}$ to a $70 \mathrm{Li}_{2} \mathrm{~S}-30 \mathrm{P}_{2} \mathrm{~S}_{5}$ electrolyte was shown to enhance the stability of the electrolyte at high temperatures $\left(100^{\circ} \mathrm{C}\right)$ (Mo et al., 2016). These examples demonstrate two successful extensions of the direct electrolyte modification pathway outlined in the previous sections.

The addition of secondary electrolyte materials has also been demonstrated to improve electrochemical performance. Yamauchi et al. (2013) showed that the addition of $\mathrm{LiBH}_{4}$ at low mole fractions to an LPS electrolyte in order to create a more stable composite electrolyte in an ASSB with a lithium 
TABLE 2 | LPS-ASSB performance over the past decade.

\begin{tabular}{|c|c|c|c|c|c|}
\hline Electrolyte & Cathode| Anode & Voltage (c-rate) & Cap.intial (mAh/g) & Cycles (\% retention) & References \\
\hline $33 \mathrm{LiBH}_{4}-67\left(0.75 \mathrm{Li}_{2} \mathrm{~S}-0.25 \mathrm{P}_{2} \mathrm{~S}_{5}\right), \mathrm{Am}$. & $\mathrm{Ti}_{2} \mathrm{~S} \mid \mathrm{Li}$-metal & $\sim 2.1$ & 200 & $5(98)$ & Yamauchi et al., 2013 \\
\hline $90\left(0.7 \mathrm{Li}_{2} \mathrm{~S}-29 \mathrm{P}_{2} \mathrm{~S}_{5}-0.01 \mathrm{WS}_{2}\right)-10 \mathrm{LiBr}, \mathrm{Am}$ & LCO| (Li-In alloy) & $2.0-3.8(0.1)$ & 130 & $100(82)$ & Zhang et al., 2019 \\
\hline $70 \mathrm{Li}_{2} \mathrm{~S}-30 \mathrm{P}_{2} \mathrm{~S}_{5}, \mathrm{Am} .-\mathrm{Cer}$ & LCO| Graphite & $3.0-4.1(0.1)$ & 100 & $100(64)$ & Ohtomo et al., 2013c \\
\hline $75 \mathrm{Li}_{2} \mathrm{~S}-30 \mathrm{P}_{2} \mathrm{~S}_{5}, \mathrm{Am}$ & LCO| Graphite & $3.0(0.1)$ & 106 & $100(65)$ & Ohtomo et al., 2013c \\
\hline $75 \mathrm{Li}_{2} \mathrm{~S}-25 \mathrm{P}_{2} \mathrm{~S}_{5}+\mathrm{Li}_{10} \mathrm{GeP}_{2} \mathrm{~S}_{12}$, bilayer & $\mathrm{Ti}_{2} \mathrm{~S} \mid$ (Li-In alloy) & $1.5-3.0(20)$ & 60 & $5(-)$ & Shin et al., 2014 \\
\hline $70 \mathrm{Li}_{2} \mathrm{~S}-30 \mathrm{P}_{2} \mathrm{~S}_{5}, \mathrm{Am}$ & (LPS/S)| In-metal & $1.0-2.4(0.1)$ & $C_{1}=1370, C_{3}=90$ & $100\left(50 \%\right.$ of $\left.C_{3}\right)$ & Busche et al., 2016 \\
\hline $80 \mathrm{Li}_{2} \mathrm{~S}-2 \mathrm{OP}_{2} \mathrm{~S}_{5}, \mathrm{Am}$ & $\mathrm{Li}_{3} \mathrm{PS}_{4} \mid$ In-metal & $2.5(0.1)$ & 220 & $30(68)$ & Hakari et al., 2015 \\
\hline $95\left(70 \mathrm{Li}_{2} \mathrm{~S}-30 \mathrm{P}_{2} \mathrm{~S}_{5}\right)-5 \mathrm{Li}_{3} \mathrm{PO}_{4}$, Am.-Cer & LNbO/LCO| Li-metal & $2-4.2(0.1)$ & 71 & $100(90)$ & Mo et al., 2016 \\
\hline
\end{tabular}

All cathodes include conductive carbon as well. Am. - Amorphous, Cer.-Ceramic. $L C O=L \mathrm{CCOO}_{2}, \mathrm{LNbO}=\mathrm{LiNbO}, \angle T O=L i T i O_{3}$.

metal anode. While the operating potential was limited due to the use of a $\mathrm{Ti}_{2} \mathrm{~S}$ cathode, the cell did show enhanced cyclability over a pure LPS electrolyte. Zhang and coworkers took a similar route by doping an LPS electrolyte with $\mathrm{LiBr}_{2}$ and $\mathrm{WS}_{2}$ to promote a reduction in internal polarization and enhanced conductivity in an ASSB with an $\mathrm{LiCoO}_{2}$ cathode and Li-In alloy anode (Zhang et al., 2019). The resultant composite electrolyte demonstrated excellent cyclability which the authors attributed to a reduction in space charge polarization at the electrode/electrolyte interfaces. The origin of the reduction in polarization was drawn from dielectric spectral sampling across a wide range of frequencies which allowed for separation of the different fast and slow polarization mechanisms such as internal dipoles and interfacial space charge, respectively. Such a frequency dependent techniques will likely play a vital role in characterizing the interfaces of ASSBs as the technology continues to mature (Tan et al., 2020).

In order to increase the stability against both the high potential cathode and reducing anode, it is possible to layer the electrolyte such that neither individual electrolyte must be stable against the entire potential window so long as their stability windows overlap and are selected appropriately for the electrodes of interest. This was demonstrated by Shin and coworkers by layering a crystalline $\mathrm{Li}_{10} \mathrm{GeP}_{2} \mathrm{~S}_{12}$ (LGPS) with an LPS electrolyte, where the LGPS was interfaced only with the cathode $\left(\mathrm{Ti}_{2} \mathrm{~S}\right)$ and LPS, with the LPS interfacing with the LGPS and the Li-In alloy anode (Shin et al., 2014). The resulting battery had excellent conductivity, suggesting that it is possible to layer with the ease of processing afforded by NCEs to produce high performing batteries. Most exemplary was the retention of $25 \%$ of the theoretical capacity when cycled at $20 \mathrm{C}$. Additional demonstrations of LPS electrolytes is ASSBs have shown enhanced capacities by making use the sulfur redox reaction (Busche et al., 2016) or a $\mathrm{Li}_{3} \mathrm{PS}_{4}$ cathode which is similar to the LPS electrolytes in question (Hakari et al., 2015).

\section{LITHIUM PHOSPHORUS OXYNITRIDE}

The second major glassy SSE of focus for this review is the lithium phosphorus oxynitride (LiPON) non-crystalline SSE material. LiPON, first reported in the 1990s (Bates et al., 1992, 1993;
Yu et al., 1997), offers an interesting comparison to the LPS SSEs which were previously reviewed owing to its different chemistry and resultant electrical/ionic/mechanical properties. Owing to these intrinsic differences, the development of LiPON has followed a distinctly different path compared to LPS in the past decade. Juxtaposition of the properties and incipient applications of LPS versus LiPON NCEs serves to illustrate the potential of NCEs to serve a wide swathe of the next generation of battery technologies.

\section{Introduction to LiPON}

LiPON is most commonly fabricated by radio frequency magnetron (RFM) sputtering at elevated temperatures $\left(T_{\text {sputter }}>200^{\circ} \mathrm{C}\right)$ in a pure nitrogen, or $\mathrm{N}_{2}$ mixed with $\mathrm{Ar}_{2} / \mathrm{O}_{2}$, atmosphere with a $\mathrm{Li}_{3} \mathrm{PO}_{4}$ target (Bates et al., 1992). The formation of a non-crystalline $\mathrm{Li}_{x} \mathrm{PO}_{4-y} \mathrm{~N}_{y}$ structure is thought to proceed by the partial nitridation of $\mathrm{Li}_{3} \mathrm{PO}_{4}$ (Lacivita et al., 2018a); however there is an ongoing debate regarding the process which will be summarized later. The precise structure over the wide composition range also remains a somewhat open question, but it is agreed upon that the material is mainly comprised of randomly oriented, corner-sharing, $\mathrm{PO}_{4-y} \mathrm{~N}_{y}$ tetrahedra, where the nitrogen can be non-bonding to reduce the connectivity of the network. The lithium atoms are distributed randomly within the interstices of this matrix, with the conductivity of bulk showing a maxima of ca. $1.4 \times 10^{-4} \mathrm{~S} / \mathrm{cm}$ for $x$ in $\mathrm{Li}_{x} \mathrm{PO}_{4-y} \mathrm{~N}_{y}$ about three (Figure 6). The relationship between composition, structure, and conductivity is still being elucidated and will be expounded upon later in this section. The film thicknesses can range from the 10s of nanometers into the micrometer regime, based on sputtering conditions (Pichonat et al., 2010; Put et al., 2016). The processing parameters such as atmosphere (Hamon et al., 2006; Ribeiro et al., 2012; Put et al., 2016; Vieira et al., 2016), substrate temperature (Jacke et al., 2011), and target composition (Hori et al., 2014; West et al., 2016; Famprikis et al., 2019b) have been shown to effect LiPON film properties. For many compositions of LiPON, the conductivity can be as low as $1-3 \times 10^{-6} \mathrm{~S} / \mathrm{cm}$ at room temperature (electrical resistivities in the range of $10^{-8}-10^{-14} \mathrm{~S} / \mathrm{cm}$ ) (Le Van-Jodin et al., 2013; Vieira et al., 2016), which would typically not make for a practical SSE in an ASSB. However, the reduced dimensions afforded by the thin film processing techniques are well-suited for the development of microbatteries. 


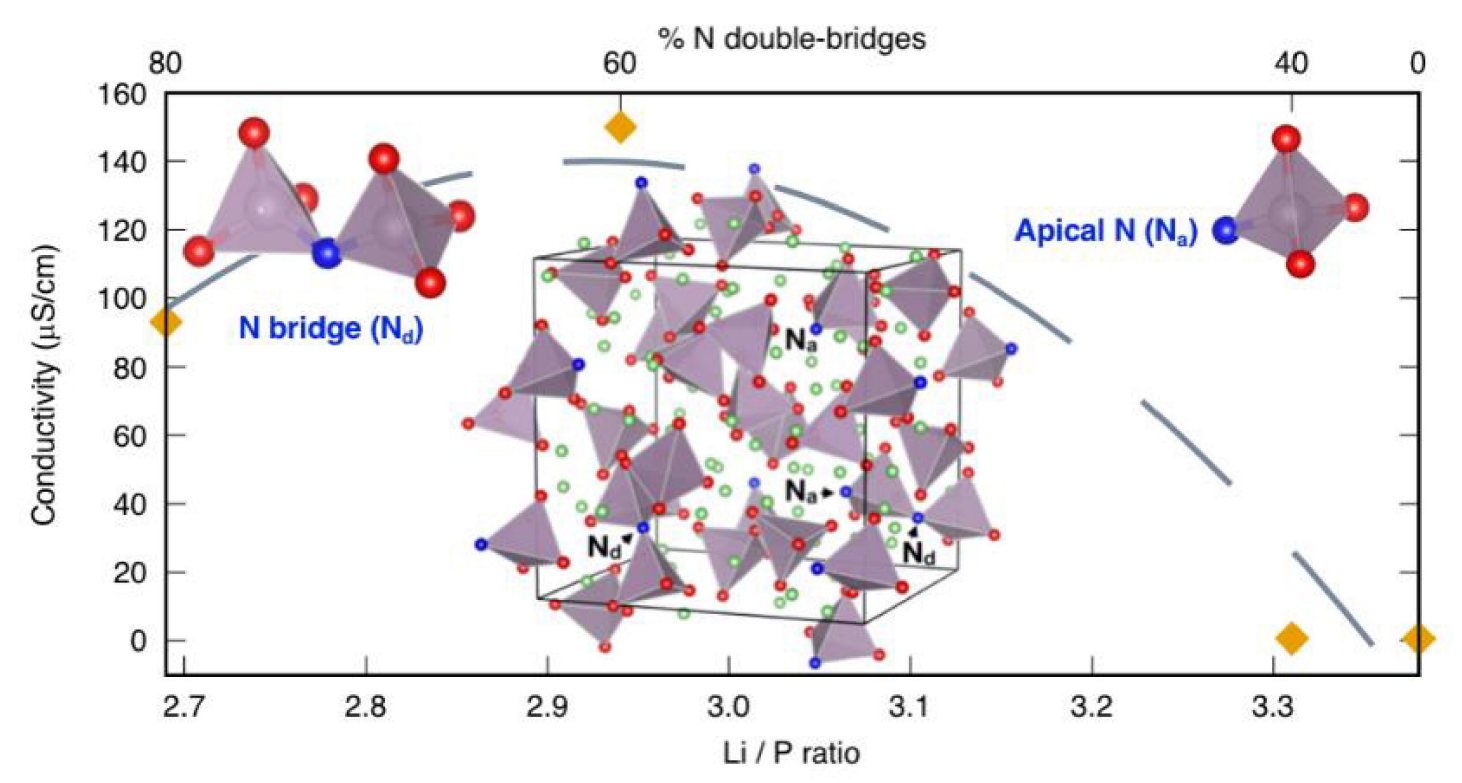

FIGURE 6 | Proposed relationship between the conductivity and composition of a LiPON system as a function of Li:P ratio. Lacivita and colleagues propose the shown structural changes in the nitrogen speciation as the dominant factor in controlling the resulting conductivity. Reprinted from Lacivita et al. (2018b) with permission from the American Chemical Society. Further permissions related to excerpted material should be directed to the American Chemical Society.

\section{Structure-Property Relationships in LiPON}

As with LPS, there is interest in understanding the relationship between the non-crystalline structure and the ionic conductivity. Based on XPS measurements of core level electrons by numerous studies in the first ca. 20 years of LiPON studies (Muñoz, 2012), many researchers believed that the nitrogen was introduced at oxygen sites as either bridging two phosphate units $\left(\mathrm{Q}^{2}\right.$ in $\mathrm{Q}^{n}$ speciation format, but often reported as $\mathrm{N}_{2}$ ) or three phosphate units $\left(\mathrm{Q}^{3}\right.$, but often reported as $\left.\mathrm{N}_{t}\right)$. Based on positive correlation between apparent increased $\mathrm{Q}^{3} \mathrm{~N}$-species and the ionic conductivity of the thin films, it has been postulated by numerous authors that the triply coordinated nitrogen is beneficial ionic conductivity (Bates et al., 1992; Yu et al., 1997). However, a number of competing explanations for the effect of $\mathrm{N}$-substitution on $\mathrm{O}$-sites have been proposed in recent years. Two papers by Lacivita et al. (2018a) extensively modeled (DFT, MD) and characterized (neutron scattering, infrared spectroscopy) to show that the increase in conductivity (from $10^{-6}$ to approximately $10^{-5} \mathrm{~S} / \mathrm{cm}$ ) with increasing $\mathrm{Li}$ and $\mathrm{N}$ content is potentially due to a number of factors, including orientational disorder of the $\mathrm{PO}_{4}$ units, excess $\mathrm{Li}^{+}$introduced at high $\mathrm{Li} / \mathrm{N}$ compositions, and bridging $\mathrm{Q}^{2}$ nitrogen lowering the electrostatic interaction between the anionic units and the mobile Li ions, with some of these factors also being identified by other workers (Pichonat et al., 2010; Fleutot et al., 2011; Famprikis et al., 2019b). Additionally, their extensive structural modeling and characterization showed no evidence for $\mathrm{Q}^{3}$ nitrogen, calling into question the previous notion of a positive correlation between of these hypothetical species to the increase in conductivity (Lacivita et al., 2018b). Rather, their results indicate that nitrogen may be present as either $\mathrm{Q}^{2}$ species or non-bridging ("apical”), bonded to one phosphate group (Figures 7A,B). These results are supported by recent XPS studies which also show that the amount of 3-coordinated nitrogen species does not correlate to increases in ionic conductivity (Mani et al., 2016). These results differ somewhat from earlier explanations of the relationship between conductivity and structure, which point instead to an increase in the amount of non-bridging oxygens (Muñoz, 2012; Mascaraque et al., 2013), a decrease in molecular $\mathrm{N}_{2}$ (Stallworth et al., 2005), or the previously mentioned $\mathrm{Q}^{3}$ nitrogen species.

In order to improve the ambient conductivity of LiPON in a commercially viable regime (ca. $10^{-6} \mathrm{~S} / \mathrm{cm}$ ), numerous studies have been devoted to the improvement of the ionic conductivity through different means. Similar to the findings pertaining to the structure of LPS discussed in the previous section, the conductivity of LiPON benefits from increasing disorder (Lacivita et al., 2018a). The increases in network former disorder can be accomplished by processing (e.g., higher deposition temperature) or compositional (introduction of non-bridging anions) means. In the case of chemical modifications, the substitution of nitrogen, silicon, or boron on oxygen sites have all been shown to be beneficial for raising the conductivity into the promising ca. $10^{-6} \mathrm{~S} / \mathrm{cm}$ range (Yoon et al., 2012; Famprikis et al., 2019b). The anionic substitutions seem to increase in the ionic conductivity and reduce the activation energy for ionic motion due to the reduction in electronegativity of the host matrix, as well as increasing the amount of non-bridging species, thereby reducing the amount of energy required for interstitial lithium ions to migrate. In concert with this effect, it has also been observed that the conductivity of LiPON films also benefits 

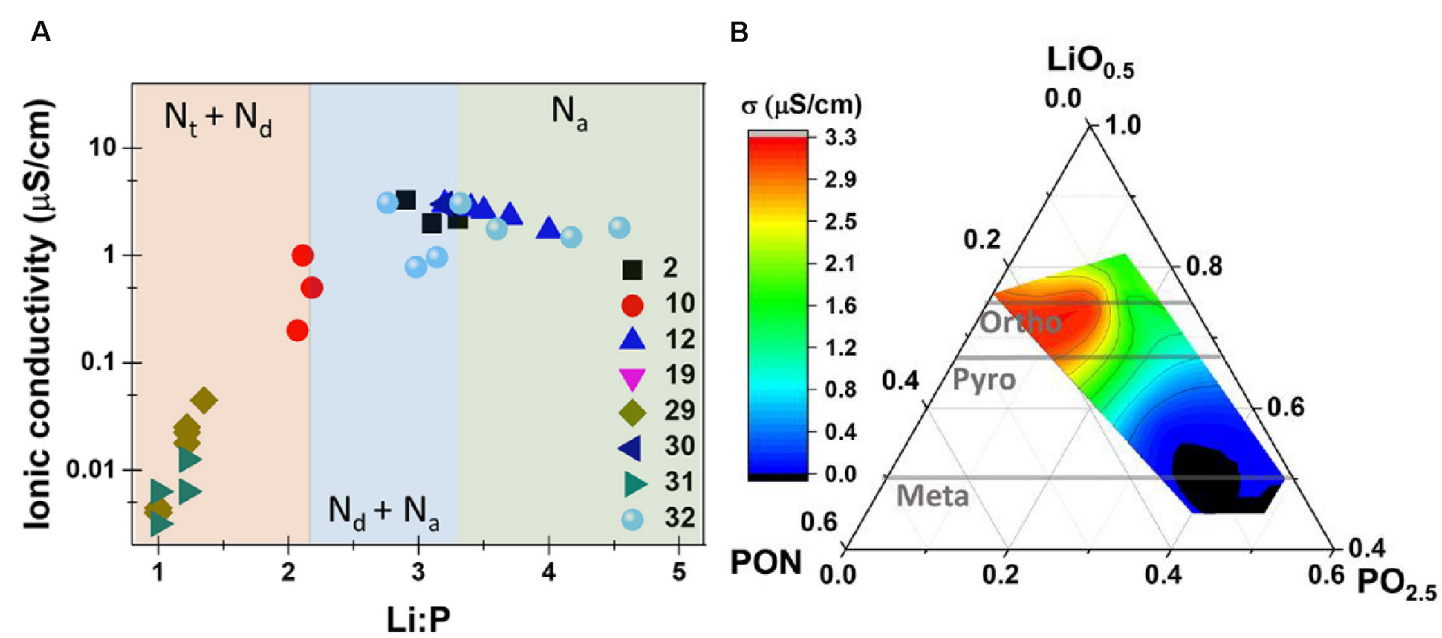

FIGURE 7 | Reconciling the changes in ionic conductivity with the Li:P ratio with an improved nitrogen speciation model with does not hinge on a triply coordinated nitrogen $\left(\mathrm{N}_{t}\right) \mathbf{( A )}$ and the proposed ternary phase diagram for LiPON (B). Reprinted with permission from Lacivita et al. (2018b). Copyright 2018 American Chemical Society.

from the introduction of excess lithium during processing, which presumably increases the concentration of interstitial lithium available for conduction (Xiao et al., 2018). Interestingly, these effects can be realized with the obvious commensurate changes in precursor (i.e., sputtering target) chemistry, but also by changing the processing atmosphere and sputtering parameters (Xiao et al., 2018; Put et al., 2019). With so many possible factors contributing to the conductivity of LiPON, it is perhaps unsurprising that the measured conductivities of LiPON of the same nominal composition can vary up to three orders of magnitude when different processing techniques are employed and the data are collated (Famprikis et al., 2019b).

The studies reviewed above do not discuss effects of structure and conductivity within the emerging framework of electrolyte theory rooted in glass relaxation behavior (Wilkinson et al., 2020). Understandably, the explanations given thus far have been largely based on relationships between the directly measurable/calculable structural characteristics such as Li-diffusion volume (Mascaraque et al., 2013), changes in anionic interactions from structural modifications (Mani et al., 2016; Lacivita et al., 2018a,b), or defect formation energies (Sicolo and Albe, 2016; Sicolo et al., 2017). The present phenomenological understanding of the relationship between structure and conductivity suffice to explain general trends seen within the LiPON literature; however, their mutual contradiction and empiricism preclude major contributions to a more general understanding of ionic conduction in the noncrystalline state. To the best of the authors' knowledge, only a singular study by Le Van-Jodin et al. (2013) does provide evidence for an increase in $\mathrm{Li}^{+}$mobility in LiPON (constant carrier concentration, ca. $0.4 \mathrm{~mol} \%$ of Li contributes to $\sigma$ ) with increasing temperature indicating LiPON behaves as a 'strong electrolyte.' The recent advances in computational modeling and experimental determination of conduction mechanisms may enable subsequent studies which may further elucidate the relationship between the structural units of LiPON and its ionic conduction mechanisms.

\section{Stability of LiPON}

An ASSB with a LiPON electrolyte fabricated by sputtering on an alumina substrate (Wang et al., 2016) (a). Potential decomposition reactions as a function of potential in a TiN| LiPON| Au system (b) as well as the I-V response showing breakdown for positive and negative potentials, with an inset at magnifying the lower potentials (c). Panel (a) reprinted with permission from Wang et al. (2016). Copyright (2016) American Chemical Society. Panels (b-c) adapted from Put et al. (2018) with permission from the Royal Society of Chemistry (Figure 8).

Concurrent with the fundamental investigations of LiPON, a number of studies have extended the scope to the stability of LiPON in different atmospheres and in contact with different electrodes. The ability of LiPON to be sputtered as a thin film allow for high interfacial contact as shown in Figure 8A. We now review some of the major findings and emerging themes from these studies to provide context for the subsequent review of LiPON-based ASSBs.

Early reports of LiPON suggested that the material was stable in contact with metallic Li over a stability window of $5.5 \pm 0.2 \mathrm{~V}$ (Yu et al., 1997); however this has been questioned in subsequent studies. The propensity of LiPON to decompose when in contact with a number of different materials has been investigated, including metallic lithium (Motoyama et al., 2015, 2018; Sicolo et al., 2017; Westover et al., 2019), the ubiquitous $\mathrm{LiCoO}_{2}$ cathode (Li et al., 2014; Schwöbel et al., 2015; Sicolo and Albe, 2016; Wang et al., 2016; Fingerle et al., 2017; Weiss et al., 2019), and the nickel manganese spinel (West et al., 2016; Thai and Lee, 2017; Lv et al., 2020). While one of LiPONs strengths as an electrolyte appears to be its resistance to lithium penetration (Westover et al., 2019), there are a number of interfacial reactions which yield gaseous evolution (Put et al., 2018) and resistive interfacial layers 
A

B

C

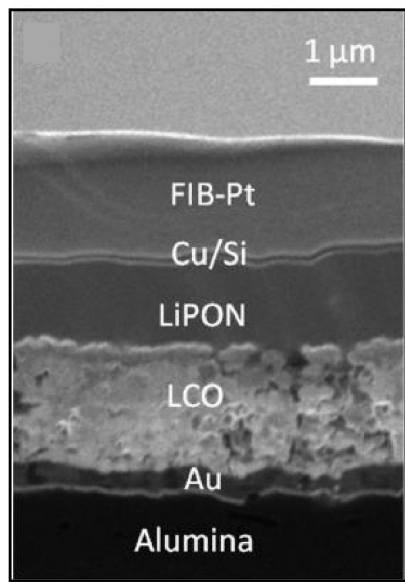

B

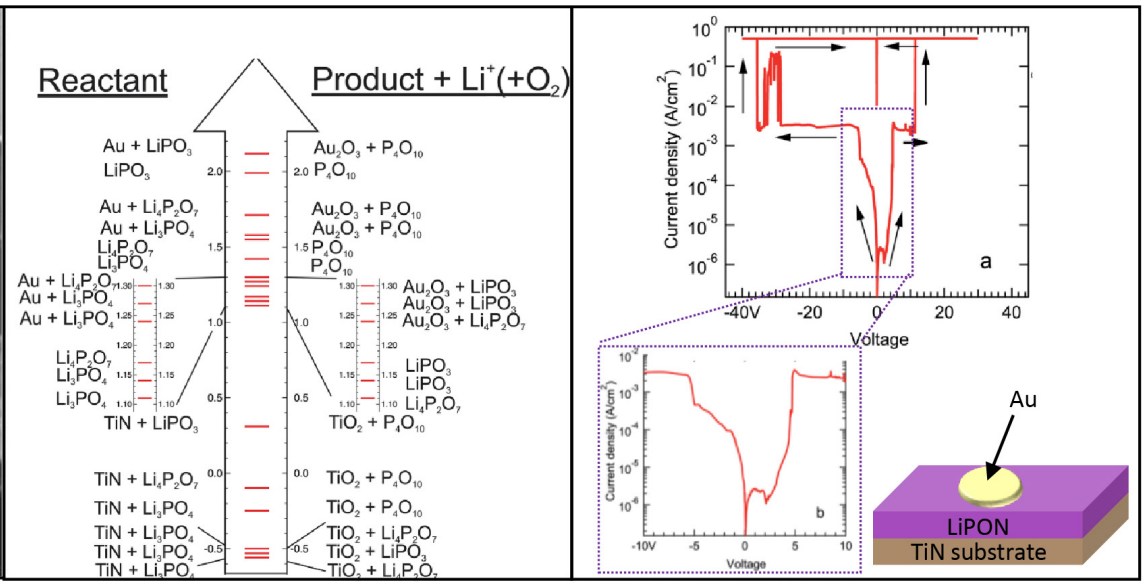

FIGURE 8 | An ASSB with a LiPON electrolyte fabricated by sputtering on an alumina substrate (Wang et al., 2016) (A). Potential decomposition reactions as a function of potential in a TiN| LiPON| Au system (B) as well as the I-V response showing breakdown for positive and negative potentials, with an inset at magnifying the lower potentials (C). (A) Reprinted with permission from Wang et al. (2016). Copyright (2016) American Chemical Society. (B,C) Adapted from Put et al. (2018) with permission from the Royal Society of Chemistry.

(Li et al., 2014; Hausbrand et al., 2015; Weiss et al., 2019) at both the anode and cathode interfaces which may limit the future application of LiPON SSEs.

Although LiPON does not exhibit unequivocal stability against decomposition reactions, it does demonstrate excellent stability against lithium metal penetration relative to other SSEs. The origin of this remarkable lithium penetration resistance has been explored from a thermodynamic standpoint (Zhu et al., 2015) and more recently by neutron scattering (Han et al., 2019). In the latter case, the authors argue that the increased resistance to lithium penetration in LiPON stems not from the surface roughness or mechanical strength, as was previously thought, but rather the exceedingly high electrical resistance of the material (ca. $10^{-15}-10^{-12} \mathrm{~S} / \mathrm{cm}$ ) (Le Van-Jodin et al., 2013; Su et al., 2015).

The practical reality of solid electrolytes, such as LiPON, is that their stability varies with the interfacing electrode and the applied bias. An example of this is shown in Figures 8B,C where Put et al. (2018) measured the I-V response of a LiPON electrolyte on a TiN substrate with a gold electrode. The breakdown response was traced to lithium liberation which then reacted with ions from either electrode, sometimes producing gas in the process. In ascribing degradation reactions, the authors used thermodynamic data for $\mathrm{Li}_{3} \mathrm{PO}_{4}$ instead of LiPON due to the lack of available thermodynamic data on LiPON. The degradation of LiPON seems to lead to ionically conductive phases such as $\mathrm{Li}_{4} \mathrm{P}_{2} \mathrm{O}_{7}$ which also explains why the stability of LiPON seems to extend beyond what some thermodynamic calculations have suggested (Zhu et al., 2015; Richards et al., 2016). Reactions with ambient atmosphere have also been shown to reduce the conductivity of LiPON to $9.9 \times 10^{-10} \mathrm{~S} / \mathrm{cm}$ through the release of $\mathrm{PH}_{3}$ and $\mathrm{NH}_{3}$ (Nimisha et al., 2011). Thus, while LiPON does show excellent stability against lithium dendrite penetration in ASSBs, both computational and experimental studies will be necessary to understand truly understand the limits of LiPON and compatible electrodes for ASSBs.

Experimental observations of the Li| LiPON interface largely agree with the findings outlined above. Schwöbel et al. (2015) observe $\mathrm{Li}_{2} \mathrm{O}$ formation at such an interface with XPS due to the decomposition of LiPON, but the resulting passivation layer does not completely destroy LiPON and prevent adequate cycling behavior. Reactions at the LiPON| Li interface are related to the difference in each material's respective chemical potential, leading to a driving force for creation of defects in LiPON (Sicolo and Albe, 2016). Advances in DFT and MD simulation techniques and computational power have allowed for simulation of these interfaces and calculation of the relative energetic favorability for the formation and migration of defects at such interfaces (Sicolo and Albe, 2016; Sicolo et al., 2017). Results from Sicolo et al. (2017) show an energetic preference for lithium interstitials at LiPON| Li interfaces, with neutral lithium interstitials competing with charged point defects leading to reduction of LiPON. This proposed mechanism of LiPON degradation when in contact with metallic $\mathrm{Li}$ agrees with experimental observations and calculated to be absent in LiPON| $\mathrm{LiCoO}_{2}$ interfaces.

Potential ASSB anodes are not limited to metallic lithium; amorphous silicon and lithium alloys are also being explored as potential ASSB anode materials (Dunn et al., 2011). Si-anodes are known to react when in contact with common non-aqueous electrolytes (Goriparti et al., 2014), so the prospect of a LiPON interlayer (i.e., Si| LiPON| liquid electrolyte) has attracted some attention. Weiss et al. (2019) showed that the resulting interphase layer(s) formed at the interface of the protective LiPON and the liquid electrolyte was ionically resistive but semi-porous, thus gradually reducing capacity and rate performance as the interfacial layer "pinholes" were filled in during cycling. Despite the formation of progressively resistive layers on Si-anodes, 
numerous recent demonstrations of ASSBs with Si| LiPON interfaces show higher capacity retention and rate performance than Si| liquid electrolyte counterparts (Hamedi Jouybari and Berkemeier, 2016; Zhou et al., 2017; Luo et al., 2018; Reyes Jiménez et al., 2018). A similar protective effect of LiPON on $\mathrm{Sn}_{x} \mathrm{~N}_{y}$ has also been demonstrated (Li et al., 2014).

In addition to the chemical stability of LiPON| Li interfaces, an SSE candidate must also demonstrate the ability to resist Li penetration ("dendrite") during cycling. LiPON excels in this respect as shown by Westover et al. (2019) where lithium "trees" are able to grow unimpeded for millimeter lengths between current collector fingers but are stopped when the $\mathrm{Li}$ is deposited and confined to an 'artificial' LiPON| LiPON interface (Figures 9A-D). As mentioned earlier in this section, the high electrical resistance of LiPON likely plays a dominant role in imparting an increased resistance to the lithium penetration, but Swamy and others have also pointed to the deposition of LiPON through sputtering as an effective means to create flush and defect-less interfaces which may also contribute to the resistance to lithium penetration from a solely mechanical strength perspective (Porz et al., 2017). The demonstration of lithium confinement to a sputtered LiPON interface bodes well for the prospect of using LiPON SSEs in thin film batteries with long cycle life (Wang et al., 2019).
The mechanical properties of LiPON films are also of interest when considering the differences in volumetric expansion during ASSB cycling and the potential for flexible batteries, so workers have also investigated the cathode| LiPON (Herbert et al., 2011; Thai and Lee, 2017) and current collector| LiPON interfaces (Motoyama et al., 2015) for evidence of mechanical failure, as well as the effect of mechanical strain on the electrical response on LiPON SSEs (Glenneberg et al., 2017). The hardness and the modulus of LiPON were measured via nanoindentation to be 3.9 $\mathrm{GPa}\left(4.1 \mathrm{GPa}\right.$ after $200^{\circ} \mathrm{C}$ anneal) and $77 \mathrm{GPa}$, respectively (Herbert et al., 2011), but it should be noted that the temporal changes in mechanical properties indicates a potentially uninvestigated creep mechanism in LiPON. Interestingly, with mechanical stress applied via bending LiPON around a known radius, the conductivity increases and the activation energy decreases as the mechanical load is increased (Glenneberg et al., 2017). However, the activation energy of hopping in LiPON is observed to increase under compressive loads (LiPON| Li-NiMn spinel interface) (Thai and Lee, 2017), suggesting that the mechanoelectrical response of LiPON may be system specific.

Finally, the interfacial stability of LiPON interfaced a number of cathode materials is addressed. Computational results contrasting $\mathrm{LiPON} \mid \mathrm{Li}$ and $\mathrm{LiPON} \mid \mathrm{LiCoO}_{2}$ interfaces show differences in the defect formation energies, and consequently
A

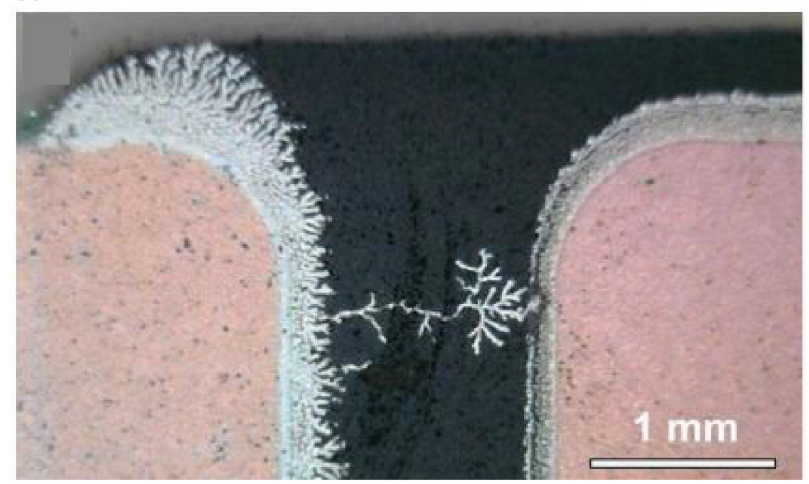

C

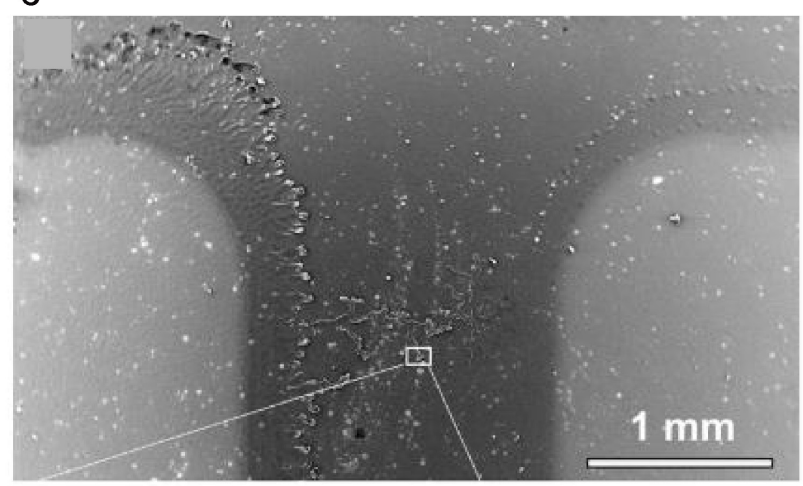

B

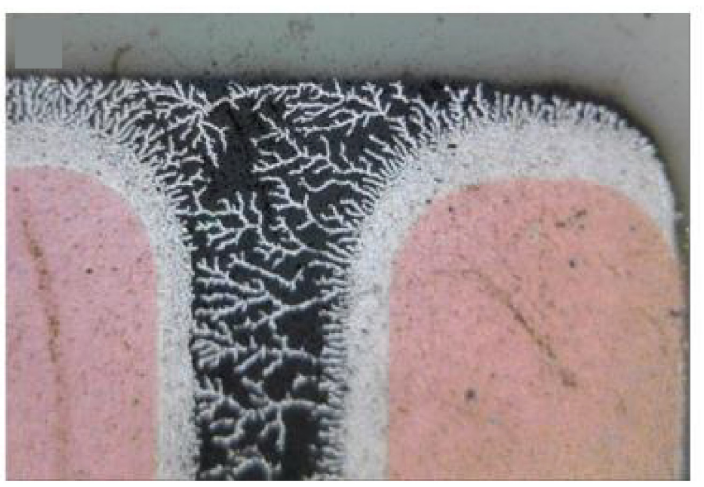

D

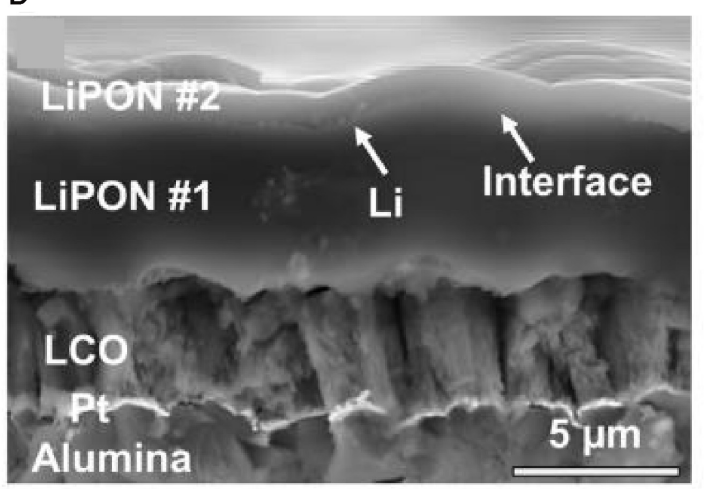

FIGURE 9 | Optical images of lithium penetration arrest with an artificial LiPON layer (A,B). SEM images of the artificial LiPON interface shows confinement of Li-metal to the nanometric interceding distance between the two layers, proving LiPONs ability to resist lithium incursion to remarkable length scales (C,D). Reprinted from Westover et al. (2019) with permission from the American Chemical Society. Further permissions related to excerpted material should be directed to the American Chemical Society. 
varied decomposition modes in LiPON in the two cases (Sicolo and Albe, 2016; Sicolo et al., 2017). These calculations are based on the chemical potential differential at the interface, so it follows that the results of these simulations/calculations can only be used to interpret experimental results only when differences in interfacial quality and composition are accounted for. Indeed, numerous studies have investigated the $\mathrm{LiPON} \mid \mathrm{LiCoO}_{2}$ via XPS (Jacke et al., 2010; Song et al., 2011b; Li et al., 2014; Schwöbel et al., 2015; Fingerle et al., 2017) and TEM (Wang et al., 2016) observe general agreement in LiPON decomposition predicted by computational methods, but also show some differences which are tenuously attributed to unavoidable differences in processing. Consistent with defect equilibria calculations, LiPON in the proximity of the $\mathrm{LiCoO}_{2}$ interface is observed to be significantly delithiated under open circuit conditions, and effect that is magnified upon the first cell cycling. However, the consequences of an unstable under-lithiathed interface are seen to somewhat differ; Wang and colleagues observe using (S)TEM/EELs a disordered layer $(\sim 3 \mathrm{~nm})$ in the $\mathrm{LiCoO}_{2}$ layer which is thought to be comprised of $\mathrm{Li}_{2} \mathrm{O}, \mathrm{Li}_{2} \mathrm{O}_{2}$, and $\mathrm{CoO}$, while XPS results of a similar study observe $\mathrm{Co}_{3} \mathrm{O}_{4}, \mathrm{Li}_{3} \mathrm{PO}_{4}$, and network-modified LiPON (Fingerle et al., 2017). While there seems to be agreement in the observations of oxygen substitutions in LiPON within proximity of the interface (Jacke et al., 2010; Song et al., 2011b; Schwöbel et al., 2015), the interfacial phases formed at the reactive layer appear to differ based on slight differences in processing. Regardless of the precise nature of the reactive layer, the resistivity of the interface often reaches as high as $10^{7} \mathrm{~S} / \mathrm{cm}$, greatly diminishing reversible battery performance (Yada et al., 2014). Yada et al. (2014) used $\mathrm{BaTiO}_{3}$ nanoparticles dispersed at the LiPON| $\mathrm{LiCoO}_{2}$ interface to counteract the presupposed space charge formed at the interface, effectively reducing the interfacial resistance to values in the range of $200 \mathrm{~S} / \mathrm{cm}$. As a result, the rate performance and gross capacity were increased relative to the ASSB with an unmodified interface. This example of interfacial modification toward improved ASSB performance epitomizes the opportunity for engineering the electrolyte| electrode interface in the next decade of ASSB research.

Similar interfacial reactions are observed when cathodes other than $\mathrm{LiCoO}_{2}$ are used. The alternative cathodes extent beyond the $\mathrm{LiCoO}_{2}$ paradigm to usher in a new era of SIB performance, such as higher voltage $(5 \mathrm{~V})$ cathodes in the case of the $\mathrm{LiNi}_{0 .} \mathrm{Mn}_{0} \cdot{ }_{5} \mathrm{O}_{4}$ spinel (Li et al., 2015). Thus, the interfacial stability of LiPON with these materials has also been explored. Redox reactions of the transition metal ions (such as Ti in $\mathrm{LiTiO}_{3}$ and LATP, $\mathrm{Mn}$ in Li-Ni-Mn spinel) is commonly observed (Guhl et al., 2017; Thai and Lee, 2017; Sepúlveda et al., 2019; Lv et al., 2020). Increases in glass transition and fictive temperature with imparted by increases in the deposition temperature appear to decrease the capacity and rate performance of these ASSBs (Sepúlveda et al., 2019). Protective cathode coatings of LiPON are beneficial for the protection of $\mathrm{NiFe}_{2} \mathrm{O}_{4}$ (Wei et al., 2018), $\mathrm{LiNi}_{0.5} \mathrm{Mn}_{0.5} \mathrm{O}_{4}$ spinel (Lv et al., 2020), and LATP (Guhl et al., 2017) by respectively reducing the cathode volume expansion during cycling, a reduction in the extent of $\mathrm{Mn}$-dissolution into a bulk liquid electrolyte, and reduction in interfacial resistance compared to systems without a LiPON coating. These recent results, in conjunction with the promising results from the LiPON-protected silicon anodes, suggest that LiPON may not only play a promising role as a standalone SSE, but also as a buffering layer at electrochemically sensitive interfaces.

Finally, a brief review of some important electrochemical performance metrics in ASSBs utilizing LiPON NCEs in Table 3. The dimensions of these batteries are often on the millimeter to centimeter in area while in the micrometer regime in thickness, so the reversible capacity is often also reported by accounting for the reduced dimensions, i.e., in $\mu \mathrm{A} \cdot \mathrm{h} / \mathrm{g}$ rather than $\mathrm{mA} \cdot \mathrm{h} / \mathrm{g}$. Further, the volumetric capacity is often reported rather than specific gravimetric capacity (as is typical in bulk ASSBs) due to the unique configurations of these microbatteries. The presented batteries demonstrate the ability to sputter the cathodes as well, which include LCO, LTO (Put et al., 2019), and LNMO (Yada et al., 2014) thin films. These batteries are typically supported by hard substrates such as $\mathrm{SiO}_{2}$ or flexible substrates (Song et al., 2010) to impart flexibility to the thin film battery as a whole. In the simplest form, LCO-LiPON-Li ASSBs demonstrate modest capacities of approximately $55 \mu \mathrm{A} \cdot \mathrm{h} / \mathrm{cm}^{2} \cdot \mu \mathrm{m}^{1}$ between voltages of around 3.5 to $3.9 \mathrm{~V}$. The cyclability, however, is much improved over the bulk ASSBs based on LPS NCEs (Table 2). Many of the reviewed ASSBs demonstrate cyclability retention of over $90 \%$ for 100 cycles, with recent reports of greater than $80 \%$ cycle retention over 900 cycles (Tintignac et al., 2014; Song et al., 2016). This cyclability is attributable to the excellent electrochemical stability at both interfaces and intrinsic resistance to Li-penetration. Furthermore, this stability is retained at high rate-performances up to $2 \mathrm{C}$ (Yada et al., 2014)

TABLE 3 | ASSBs with a LiPON (or LiBON) electrolyte and the electrochemical properties of the cells with a lithium anode.

\begin{tabular}{|c|c|c|c|c|c|}
\hline Electrolyte & Cathode| Anode & Voltage (C-rate) & Approximately initial capacity & Cycles (\% Ret.) & References \\
\hline LiPON-BaTiO3 & LNMO| Li & $3.5-4.9(2.0 \mathrm{C})$ & $81 \mathrm{mAh} / \mathrm{g}$ & $100(104)$ & Yada et al., 2014 \\
\hline Li-LiPON & $\mathrm{LCO} \mathrm{Li}$ & $3.2-4.2(0.1 \mathrm{C})$ & $64.5 \mu \mathrm{Ah} / \mathrm{cm}^{2}$ & $5(98)$ & Xiao et al., 2019 \\
\hline LiPON & LTO| Li & $1.5(5 \mathrm{C})$ & $0.3 \mathrm{Ah} / \mathrm{cm}^{3}$ & $500(-)$ & Put et al., 2019 \\
\hline LiPON & LCO| Li & $3.0-4.2(0.4 \mathrm{C})$ & $50 \mu \mathrm{Ah} / \mathrm{cm}^{2 \star} \mu \mathrm{m}^{1}$ & $140(91)$ & Song et al., 2011a \\
\hline LiPON & LCO| Li & $3.0-4.2(0.4 \mathrm{C})$ & $50 \mu \mathrm{Ah} / \mathrm{cm}^{2 \star} \mu \mathrm{m}^{1}$ & $900(84)$ & Tintignac et al., 2014 \\
\hline LiBON & LCO| Li & $3.0-4.2(1 \mathrm{C})$ & $49 \mu \mathrm{Ah} / \mathrm{cm}^{2 \star} \mu \mathrm{m}^{1}$ & $1000(90)$ & Song et al., 2016 \\
\hline LiPON & LNMO| Li & $3.4-4.9(0.2 \mathrm{C})$ & $60 \mathrm{~mJ} / \mathrm{cm}^{2}$ & $20(83)$ & Yim et al., 2020 \\
\hline
\end{tabular}

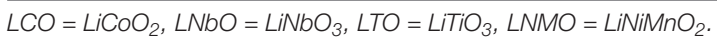


and $10 \mathrm{C}$ (Song et al., 2010). In the former, this high rate performance is attained by the previously described reduction in interfacial resistance by the addition of a dielectric to the electrode| electrolyte interface. The capacities of these batteries are limited by the thickness and specific capacity of the cathode materials (Julien et al., 2019), so it remains to be seen if thin film LiPON-based ASSBs can make use of the next generation cathodes being developed in parallel. Over the course of the next decade, improvements to the specific capacities of these thin-film ASSBs enabled by next-generation technology will play a pivotal role in enabling the forthcoming "internet of things."

\section{INSIGHTS INTO IONIC CONDUCTION IN THE NON-CRYSTALLINE STATE}

The bulk of the ASSB SIB literature of the past decade has centered around practical demonstrations and directly quantifiable improvements to energy storage metrics such as specific capacity, interfacial stability, operating potential, etc. (Lin et al., 2018). The potential for broader impact of NCEs is not limited to enabling next generation lithium SIBs, such as the parallel advances being made in proton conducting glasses for fuel cell electrolytes (Uma and Nogami, 2008; Yamaguchi et al., 2018; Omata et al., 2019). In the final section of this review, the focus is shifts to advances in understanding the fundamental mechanism and theory of ionic conduction in the non-crystalline state. Having developed a mature theory of ionic conduction in liquid electrolytes (Bockris, 1998), and with a similarly robust theory of ionic conduction in the crystalline state proving elusive (Bachman et al., 2015), perhaps insight into ionic conduction mechanisms in the glassy state, may be a necessary step toward a generalized theory of ionic conduction in solid-state systems.

\section{Structural Relations}

A number of differing explanations for ionic conduction in non-crystalline materials have been proposed. Prior to ca. 2010, part of the debate centered on whether the conducting ions where dispersed randomly (Swenson et al., 1998; Adams and Swenson, 2000) or in salt clusters (Malugani and Robert, 1979; Mercier et al., 1981) throughout the structure. As shown throughout this review, the recent combinatory advances in structural characterization and modeling have shed light on such questions, showing that in many common glass systems (e.g., alkali binary silicates, phosphates, sulfides) cations are distributed mostly randomly throughout a glass structure, i.e., not generating percolated areas of conductive alkali salts in an otherwise non-conducting matrix (Swenson et al., 1998). The long-range structure of the glass is thus generally unaffected at low alkali concentrations, and thus attention has turned toward the short-range structural changes which enable and effect ionic conductivity.

It has been shown throughout this review that the presence and concentration of alkali network modifiers can stabilize non-bridging species including silicate oxides, phosphates, and nitrides. In the case of aluminoborosilicate systems, the mobility and conductivity of the bulk glass is greatly affected by the sites upon which the alkali modifier sites (Smedskjaer et al., 2011). Similarly, in LiPON, the studies reviewed in this manuscript extensively drew on structural modifications induced by nitridation of the Li-P-O glass. However, as shown in recent studies by Lacivita et al. (2018b) and expounded upon by Muñoz (Muñoz, 2012), interpretation of the structural characterizations in LiPON (and related non-crystalline electrolytes) is nontrivial, so there remains much work to be done in reaching a broad consensus of the relation between characteristic glass species (such as non-bridging oxygens and triply coordinated nitrogen) and the resulting changes in ionic conductivity and activation energies.

Structural relationships have often been used to try to justify the origin of the activation barrier, in an attempt to both discover atomistic origins of conductivity but also in order to increase the predictability of new compositions' transport behavior. In the liquid state (when $T>>T_{g}$ ) it is known that the commonly used Stokes-Einstein relationship accurately describes the diffusion when an accurate viscosity model is used, such as the MYEGA equation (Mauro et al., 2009b). The Stokes-Einstein relates the diffusivity with the viscosity through a constant (a) at a temperature $T$,

$$
D=\frac{a T}{\eta}
$$

This is a powerful model since viscosity can be modeled as a function of composition using topological constraint theory (TCT). A wide range of review papers on TCT are available and as such will not be discussed extensively here (Smedskjaer et al., 2010; Mauro, 2011; Bauchy, 2012). All viscosity models require three parameters to describe the temperature dependence of viscosity: the fragility $(m)$, the glass transition $\left(T_{g}\right)$ and the infinite temperature limit of viscosity, which is a constant of $10^{-2} .{ }^{97} \mathrm{~Pa} \cdot \mathrm{s}$ (Zheng et al., 2011). Fragility and $T_{g}$ can be both written in terms of the degrees of freedom per atom of a glass $(f)$ at the glass transitions with the glass transition given by,

$$
f(T, x) T_{g}(x)=\text { const } .
$$

The fragility is given by the expression (Mauro et al., 2009a),

$$
m(x)=m_{0}\left(1+\left.\frac{\partial \ln f(x, T)}{\partial \ln T}\right|_{T=T_{g}(x)}\right)
$$

These terms and some parametrization of the constant, $a$, can allow for a complete description of the diffusivity above the glass transition.

To relate the structure of a glass to its conductivity there first must be a unifying model for the origin of the activation barrier. Several models have been proposed, each based on either the strong or weak electrolyte model. One such model is the 'Christensen-Martin-Andersen-Stuart' model (Martin et al., 2019) based on the strong electrolyte theory where the activation energy is a linear mixing of Coulombic binding energy and a strain energy. This assumes that the ion pushes the network elastically and then jumps through the space it forms. The Coulombic binding is given a function of the Madelung constant and assumes that the distance of the ions is the sum of the radii. The strain term is directly related to the shear modulus and the jump distance of these ions. One possible way to predict 
this is to use recent advances in TCT to find relevant moduli (Wilkinson et al., 2019b); however additional work on this topic is still needed. This model provides some strong results in numerous studies but is limited by the necessity of fitting the Madelung constant. Most models that have been shown in literature have had some fitting parameter, which makes it difficult to write the activation energy of an entire glass family as a function of composition.

\section{Mounting Evidence for the Weak Electrolyte Theory}

A weak electrolyte is one in which the conductivity is governed primarily by the concentration of charge carriers, rather than their respective mobilities (see section "Noncrystalline Electrolytes"). Souquet and Ravaine proposed that this thermodynamic model was the most adequate description of ionically conducting alkali oxide glasses (Ravaine and Souquet, 1977; Souquet et al., 2010). The contending view, viz., that glasses are better described by strong electrolytes whose ionic conductivity is a function of the mobilities of the charge carriers, has also been proposed as described above (Anderson and Stuart, 1954). Recent measurements and simulations of charge carrier mobilities and concentrations have come to largely support the weak electrolyte theory, but not without notable challenges (Martin, 1991; Martin et al., 2019).

The conductivity of $\mathrm{AgI}-\mathrm{AgPO}_{3}$ glasses at temperatures below $T_{g}$ was shown to related to two barriers, the first related to charge carrier concentration and the second related to migration of said carriers (Rodrigues et al., 2011). As the concentration of $\mathrm{AgI}$ is increased, the ionic conductivity similarly increases, which the authors were able to attribute to a reduction in the carrier formation enthalpy from 0.86 to $0.2 \mathrm{eV}$ as the concentration of AgI was increased from 0 to $50 \%$. The enthalpy of migration was found to be constant $(0.14 \mathrm{eV})$ so the mobility of the charge carriers was found to also be constant at ca. $10^{-4} \mathrm{~cm}^{2} \mathrm{~V}^{-1} \mathrm{~s}^{-1}$, consistent with measurements made on similar systems by the Hall-effect technique (Souquet and Perera, 1990). These results are expanded upon in later studies of the same system (Bragatto et al., 2017), where the increase in conductivity can be related the thermal response of the dissociation constant $\left(K_{\text {diss }}\right)$ for the reaction.

$$
2 \mathrm{AgI} \stackrel{K_{\text {diss }}}{\leftrightarrow} \mathrm{Ag}_{2} \mathrm{I}^{+}+\mathrm{I}^{-}
$$

Thus, these studies which span almost 30 years point unanimously to confirmation of the weak electrolyte theory being valid for the $\mathrm{AgI}-\mathrm{AgPO}_{3} \mathrm{SSE}$. The correlation between the activity of $\mathrm{AgI}$ and composition in the $x \mathrm{AgI}-(1-x) \mathrm{AgPO}_{3}$ is shown in Figure 10A.

Very recent MD simulations of alkali silicate (Welch et al., 2019), SSEs also support the weak electrolyte hypothesis. No change in ionic mobility is observed for $x \mathrm{M}_{2} \mathrm{O}-(1-x) \mathrm{SiO}_{2}$ for $\mathrm{M}=\mathrm{Li}, \mathrm{Na}$, and $\mathrm{K}$ as $x$ or the simulation temperature is increased, so the increase in ionic conductivity is ascribed to the increase in charge carrier concentration (Figure 10B). In a nudged elastic band simulation of sodium in borate and silicate environments, the activation energy for the hopping mechanism between alkali sites was related to the cooperative relaxation of the glass network, as described by the Adam-Gibbs relationship between viscosity and relaxation (Adam and Gibbs, 1965). Assuming that the ionic conduction mechanism of weak electrolyte glasses is dependent on the local cooperative relaxation in the vicinity of the mobile ion, Wilkinson and colleagues derived the relation.

$$
\frac{E_{a}}{E_{a, r}}=\frac{T_{g, r} m_{r}}{T_{g} m}
$$

Where the activation energy for diffusion and a reference relaxation $\left(E_{a}\right.$ and $\left.E_{a, r}\right)$ are inversely proportional to the
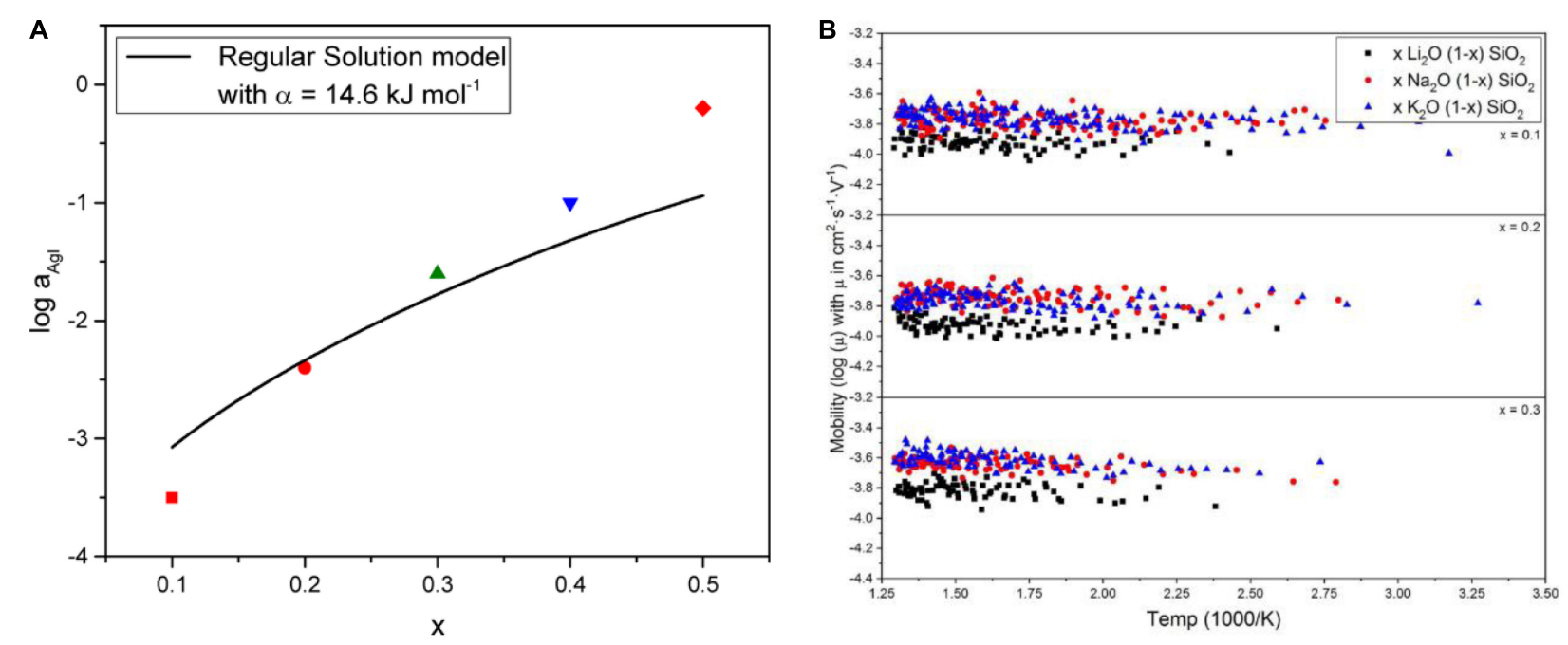

FIGURE 10 | Comparison of the measured activity in the $x \mathrm{Agl}-(1-x) \mathrm{AgPO}_{3}$ glass electrolyte system as a function of percent Agl based on a regular solution model (A) and $\mathrm{MD}$ simulation of alkali silicates, $\mathrm{M}_{2} \mathrm{O}-\mathrm{SiO}_{2}$ where $\mathrm{M}=\mathrm{Li}, \mathrm{Na}$, $\mathrm{K}$, showing no change in mobility as a function of temperature (B). (A) Reprinted (adapted) with permission from Bragatto et al. (2017). Copyright 2017, American Chemical Society. (B) Is reproduced from Welch et al. (2019), originally produced and copyrighted 2019 by Frontiers in Materials, parent companies, and the cited authors. Subject to Creative Commons Attributions License (CC BY). 
(reference) glass transition temperature, $T_{g}\left(T_{g, r}\right)$ and the fragility index (m) (Mauro et al., 2009b; Wilkinson et al., 2020). The accuracy is shown in Figure 10B. Thus, a priori calculation of the ionic conductivity can be obtained given only the three physically meaningful parameters of the MYEGA, which may be a promising route to understanding ion dynamics in noncrystalline SSEs, in addition to the design of better SSEs. This expression also shows that the glass transport properties are controlled by the same parameters of that control transport in liquids. More work is needed in both experimental confirmation of the aforementioned computational results, extension of these concepts to non-crystalline SSEs where the mobility appears to change with structure (Lacivita et al., 2018b), and reconciliation with recent alternative interpretations which cite elastic deformation of the glass network as the mechanism for ionic conduction (Martin et al., 2019).

\section{CONCLUSION}

Recent advances two non-crystalline SSEs, lithium thiophosphate (LPS) and lithium oxynitride (LiPON), were reviewed. The excellent room temperature ionic conductivities (ca. $10^{-4} \mathrm{~S} / \mathrm{cm}$ ) in LPS make it an interesting candidate bulk SSE in ASSBs. With the addition of Li-salts and other network formers/modifiers, the conductive properties of the SSE can be increased (ca. $10^{-3} \mathrm{~S} / \mathrm{cm}$ ). The conductivity can be further increased by partial or total crystallization. Recent computational and experimental studies have identified interfacial reactions between LPS-type SSEs and promising electrodes (e.g., $\mathrm{LiCoO}_{2}, \mathrm{Li}-$ metal) for ASSBs. Based on these findings, the LPS remains a strong candidate for bulk Li-based ASSBs but advances in interfacial modifications to reduce electrolyte/electrode decomposition will be needed for LPS to remain a viable option for future ASSBs.

As another example, the recent advances of LiPON SSEs were also reviewed. While the ionic conductivities are generally lower than typical superionic conductors (LiPON room temperature conductivity ca. $10^{-6} \mathrm{~S} / \mathrm{cm}$ ), the ability to easily fabricate the glass as a thin film through sputtering has resulted in its application to thin film ASSBs. The findings of recent structure-property relationships of these glasses were reviewed, in addition to its interfacial stability in ASSB prototypes. With appropriate doping and processing, LiPON is shown to be an excellent candidate for thin film ASSBs based on its stability and processability. Future

\section{REFERENCES}

Adam, G., and Gibbs, J. H. (1965). On the temperature dependence of cooperative relaxation properties in glass-forming liquids. J. Chem. Phys. 43, 139-146. doi: 10.1063/1.1696442

Adams, S., and Rao, R. P. (2009). Transport pathways for mobile ions in disordered solids from the analysis of energy-scaled bond-valence mismatch landscapes. Phys. Chem. Chem. Phys. 11:3010. doi: 10.1039/b905911n

Adams, S., and Swenson, J. (2000). Determining Ionic Conductivity from structural models of fast ionic conductors. Phys. Rev. Lett. 84, 2-5. doi: 10.1103/ PhysRevLett.84.4144 studies relating the structure of LiPON to its conductivity and stability are required to resolve ongoing debates.

Finally, a discussion recent experimental and computational studies addressing the theories and mechanism(s) of ionic conduction in the glassy was given. Studies offering support of the weak electrolyte theory of glass is given by computational and experimental results investigating the silver phosphate and sodium silicate/borate glass systems are reviewed. Furthermore, it is speculated based on recent simulations relating the ionic conduction of glasses to a cooperative relaxation (rather than a physical expansion) near a diffusing ion, that it may be possible to describe and predict the conductive properties of glassy SSEs with the MYEGA model. Additional experimental and computation studies investigating the relationship between ion conduction in non-crystalline SSEs to support or refute these notions is warranted. Thus, the study and application of non-crystalline electrolytes have benefited from the simultaneous, but ostensibly isolated, advances in glass science and solid-state energy storage of the past decade.

\section{AUTHOR CONTRIBUTIONS}

ZG conceived of the review scope and authored the LPS and LiPON sections of the manuscript. CW authored the fundamentals of ionic conduction section and contributed to all other sections. CR edited and offered technical expertise throughout the preparation of the manuscript. JM contributed to the scope and format of the review, edited the manuscript, and provided technical contributions to all portions of the manuscript. All authors contributed to the article and approved the submitted version.

\section{FUNDING}

The authors would like to thank the Air Force Office of Scientific Research (Grant No. FA9550-19-1-0372) and the Air Force Research Laboratory (grant no. FA9550-16-1-0429) for providing the funding for this work.

\section{ACKNOWLEDGMENTS}

The authors would like to thank Anthony DeCeanne for discussions regarding the glass-ceramic topics.

Ahmad, N., Zhou, L., Faheem, M., Tufail, M. K., Yang, L., Chen, R., et al. (2020). Enhanced air-stability and high Li-ion conductivity of Li6.988P2.994Nb0.2S10.934O0.6 glass-ceramic electrolyte for All-Solid-state Lithium-Sulfur Batteries. ACS Appl. Mater. Interfaces 12, 21548-21558. doi: 10.1021/acsami.0c00393

Anderson, O. L., and Stuart, D. A. (1954). Calculation of activation energy of ionic conductivity in silica glasses by classical methods. J. Am. Ceram. Soc. 37, 573-580. doi: 10.1111/j.1151-2916.1954. tb13991.x

Aoki, Y., Ogawa, K., Nakagawa, T., Hasegawa, Y., Sakiyama, Y., Kojima, T., et al. (2017). Chemical and structural changes of 70Li2S-30P2S5 solid electrolyte 
during heat treatment. Solid State Ionics 310, 50-55. doi: 10.1016/j.ssi.2017. 08.006

Aono, H., Sugimoto, E., Sadaoka, Y., Imanaka, N., and Adachi, G.-Y. (1990). Ionic conductivity of solid electrolytes based on Li1.3Al0.3Ti1.7(PO4)3. J. Electrochem. Soc. 137, 1023-1027.

Auvergniot, J., Cassel, A., Ledeuil, J. B., Viallet, V., Seznec, V., and Dedryvère, R. (2017). Interface Stability of Argyrodite $\mathrm{Li} 6 \mathrm{PS} 5 \mathrm{Cl}$ toward $\mathrm{LiCoO} 2$. LiNi1/3Co1/3Mn1/3O2, and LiMn2O4 in Bulk All-Solid-State Batteries. Chem. Mater. 29, 3883-3890. doi: 10.1021/acs.chemmater.6b04990

Aziz, S. B., Woo, T. J., Kadir, M. F. Z., and Ahmed, H. M. (2018). A conceptual review on polymer electrolytes and ion transport models. J. Sci. Adv. Mater. Devices 3, 1-17. doi: 10.1016/j.jsamd.2018.01.002

Bachman, J. C., Muy, S., Grimaud, A., Chang, H.-H., Pour, N., Lux, S. F., et al. (2015). Inorganic solid-state electrolytes for lithium batteries: mechanisms and properties governing ion conduction. Chem. Rev. 116, 140-162. doi: 10.1021/ acs.chemrev.5b00563

Balbuena, C., Montani, R., and Frechero, M. A. (2015). Is ergodicity in an oxide glass ionic conductor a matter of time? Phys. A Stat. Mech. Appl. 432, 400-409. doi: 10.1016/j.physa.2015.03.027

Bates, J. B., Dudney, N. J., Gruzalski, G. R., Zuhr, R. A., Choudhury, A., Luck, C. F., et al. (1992). Electrical properties of amorphous lithium electrolyte thin films. Solid State Ionics 5, 647-654. doi: 10.1016/0167-2738(92)90442-R

Bates, J. B., Dudney, N. J., Gruzalski, G. R., Zuhr, R. A., Choudhury, A., Luck, C. F., et al. (1993). Fabrication and characterization of amorphous lithium electrolyte thin films and rechargeable thin-film batteries. J. Power Sources 43, 103-110. doi: 10.1016/0378-7753(93)80106-Y

Bauchy, M. (2012). Topological constraints and rigidity of network glasses from molecular dynamics simulations. Am. Ceram. Soc. Bull. 91:34.

Berbano, S. S., Mirsaneh, M., Lanagan, M. T., and Randall, C. A. (2013). Lithium thiophosphate glasses and glass-ceramics as solid electrolytes: processing, microstructure, and properties. Int. J. Appl. Glas. Sci. 4, 414-425. doi: 10.1111/ ijag. 12037

Bockris, J. (1998). Modern Electrochemistry 1, 2A, 2B, 2nd Edn. New York, NY: Springer US.

Bragatto, C. B., Candida, A., Rodrigues, M., and Souquet, J.-L. (2017). Dissociation Equilibrium and Charge Carrier Formation in AgI- AgPO 3 Glasses. J. Phys. Chem. C 121, 13507-13514. doi: 10.1021/acs.jpcc.7b02477

Bunde, A., Funke, K., and Ingram, M. (1998). Ionic glasses: history and challenges. Solid State Ionics 105, 1-13. doi: 10.1016/S0167-2738(97)00444-X

Busche, M. R., Weber, D. A., Schneider, Y., Dietrich, C., Wenzel, S., Leichtweiss, T., et al. (2016). In Situ Monitoring of Fast Li-Ion Conductor Li 7 P 3 S 11 Crystallization Inside a Hot-Press Setup. Chem. Mater. 28, doi: 10.1021/acs. chemmater.6b02163

Chandra, A., Bhatt, A., and Chandra, A. (2013). Ion conduction in superionic glassy electrolytes: an overview. J. Mater. Sci. Technol. 29, 193-208. doi: 10.1016/j.jmst. 2013.01.005

Chen, S., Xie, D., Liu, G., Mwizerwa, J. P., Zhang, Q., Zhao, Y., et al. (2018). Sulfide solid electrolytes for all-solid-state lithium batteries: structure, conductivity, stability and application. Energy Storage Mater. 14, 58-74. doi: 10.1016/j.ensm. 2018.02.020

Cheng, X.-B., Zhang, R., Zhao, C.-Z., Wei, F., Zhang, J.-G., and Zhang, Q. (2016). A Review of Solid Electrolyte Interphases on Lithium Metal Anode. Adv. Sci. 3:1500213. doi: 10.1002/advs.201500213

Dietrich, C., Koerver, R., Gaultois, M. W., Kieslich, G., Cibin, G., Rgen Janek, J., et al. (2018). Spectroscopic characterization of lithium thiophosphates by XPS and XAS-a model to help monitor interfacial reactions in all-solid-state batteries †. Phys. Chem. Chem. Phys 20, doi: 10.1039/c8cp01968a

Dietrich, C., Weber, D. A., Culver, S., Senyshyn, A., Sedlmaier, S. J., Indris, S., et al. (2017a). Synthesis, structural characterization, and lithium ion conductivity of the lithium thiophosphate Li 2 P 2 S 6. Inorg. Chem. 56, 6681-6687. doi: 10.1021/acs.inorgchem.7b00751

Dietrich, C., Weber, D. A., Sedlmaier, S. J., Indris, S., Culver, S. P., Walter, D., et al. (2017b). Lithium ion conductivity in Li2S-P2S5 glasses-building units and local structure evolution during the crystallization of superionic conductors Li3PS4, Li7P3S11 and Li4P2S7. J. Mater. Chem. A 5, 18111-18119. doi: 10.1039/ c7ta06067j

Dunn, B., Kamath, H., and Tarascon, J. M. (2011). Electrical energy storage for the grid: a battery of choices. Science 334, 928-935. doi: 10.1126/science.1212741
Dyre, J. C. (1986). On the mechanism of glass ionic conductivity. J. Non. Cryst. Solids 88, 271-280. doi: 10.1016/S0022-3093(86)80030-80038

Dyre, J. C., Maass, P., Roling, B., and Sidebottom, D. L. (2009). Fundamental questions relating to ion conduction in disorded solids. Reports Prog. Phys. 72:046501. doi: 10.1088/0034-4885/72/4/046501

Eckert, H., and Martins Rodrigues, A. C. (2017). Ion-conducting glass-ceramics for energy-storage applications. MRS Bull. 42, 206-212. doi: 10.1557/mrs.2017.30

Famprikis, T., Canepa, P., Dawson, J. A., Islam, M. S., and Masquelier, C. (2019a). Fundamentals of inorganic solid-state electrolytes for batteries. Nat. Mater. 18, 1-14. doi: 10.1038/s41563-019-0431-433

Famprikis, T., Galipaud, J., Clemens, O., Pecquenard, B., Freìdeì, F., and Le Cras, F. (2019b). Composition Dependence of Ionic Conductivity in LiSiPO(N) Thin-Film Electrolytes for Solid-State Batteries. ACS Appl. Energy Mater. 2, 4782-4791. doi: 10.1021/acsaem.9b00415

Fingerle, M., Buchheit, R., Sicolo, S., Albe, K., and Hausbrand, R. (2017). Reaction and Space Charge Layer Formation at the LiCoO2-LiPON interface: insights on defect formation and ion energy level alignment by a combined surface science-simulation approach. Chem. Mater. 29, 7675-7685. doi: 10.1021/acs. chemmater.7b00890

Fleutot, B., Pecquenard, B., Martinez, H., Letellier, M., and Levasseur, A. (2011). Investigation of the local structure of LiPON thin films to better understand the role of nitrogen on their performance. Solid State Ionics 186, 29-36. doi: 10.1016/j.ssi.2011.01.006

Fukushima, A., Hayashi, A., Yamamura, H., and Tatsumisago, M. (2017). Mechanochemical synthesis of high lithium ion conducting solid electrolytes in a $\mathrm{Li}_{2} \mathrm{~S}-\mathrm{P}_{2} \mathrm{~S}_{5}-\mathrm{Li}_{3} \mathrm{~N}$ system. Solid State Ionics 304, 85-89. doi: 10.1016/j.ssi.2017. 03.010

Gao, Y., Yan, Z., Gray, J. L., He, X., Wang, D., Chen, T., et al. (2019). Polymerinorganic solid-electrolyte interphase for stable lithium metal batteries under lean electrolyte conditions. Nat. Mater. 18:1. doi: 10.1038/s41563-019-0305-308

Glenneberg, J., Bardenhagen, I., Langer, F., Busse, M., and Kun, R. (2017). Time resolved impedance spectroscopy analysis of lithium phosphorous oxynitride - LiPON layers under mechanical stress. J. Power Sources 359, 157-165. doi: 10.1016/j.jpowsour.2017.05.037

Goodenough, J. B. (1998). "General concepts," in Lithium Ion Batteries; Fundamentals and Performance, eds O. Yamamoto, and M. Wakihara (Hoboken, NJ: John Wiley \& Sons), 1-25. doi: 10.1515/9783110874372.1

Goodenough, J. B., Hong, H., and Kafalas, J. A. (1976). Fast Na+-ion transport in skeleton structures. Mater. Res. Bull. 11, 203-220. doi: 10.1016/0025-5408(76) 90077-90075

Goodenough, J. B., and Park, K.-S. (2013). The Li-ion rechargeable battery: a perspective. J. Am. Chem. Soc. 22:56. doi: 10.1021/ja3091438

Goriparti, S., Miele, E., De Angelis, F., Di Fabrizio, E., Proietti Zaccaria, R., and Capiglia, C. (2014). Review on recent progress of nanostructured anode materials for Li-ion batteries. J. Power Sources 257, 421-443. doi: 10.1016/j. jpowsour.2013.11.103

Guhl, C., Fingerle, M., and Hausbrand, R. (2017). Process related effects upon formation of composite electrolyte interfaces: nitridation and reduction of NASICON-type electrolytes by deposition of LiPON. J. Power Sources 362, 299-307. doi: 10.1016/j.jpowsour.2017.07.051

Hakari, T., Deguchi, M., Mitsuhara, K., Ohta, T., Saito, K., Orikasa, Y., et al. (2017). Structural and electronic-state changes of a sulfide solid electrolyte during the Li deinsertion-insertion processes. Chem. Mater. 29, 4768-4774. doi: 10.1021/acs.chemmater.7b00551

Hakari, T., Nagao, M., Hayashi, A., and Tatsumisago, M. (2015). All-solid-state lithium batteries with Li3PS4 glass as active material. J. Power Sources 293, 721-725. doi: 10.1016/j.jpowsour.2015.05.073

Hamedi Jouybari, Y., and Berkemeier, F. (2016). Enhancing Silicon Performance via LiPON Coating: a prospective anode for lithium ion batteries. Electrochim. Acta 217, 171-180. doi: 10.1016/j.electacta.2016.09.040

Hamon, Y., Douard, A., Sabary, F., Marcel, C., Vinatier, P., Pecquenard, B., et al. (2006). Influence of sputtering conditions on ionic conductivity of LiPON thin films. Solid State Ionics 177, 257-261. doi: 10.1016/j.ssi.2005.10.021

Han, F., Westover, A. S., Yue, J., Fan, X., Wang, F., Chi, M., et al. (2019). High electronic conductivity as the origin of lithium dendrite formation within solid electrolytes. Nat. Energy 4, 187-196. doi: 10.1038/s41560-018-0312-z

Hausbrand, R., Cherkashinin, G., Ehrenberg, H., Gröting, M., Albe, K., Hess, C., et al. (2015). Fundamental degradation mechanisms of layered oxide Li-ion 
battery cathode materials: methodology, insights and novel approaches. Mater. Sci. Eng. B Solid-State Mater. Adv. Technol. 192, 3-25. doi: 10.1016/j.mseb.2014. 11.014

Hayashi, A., Minami, K., Mizuno, F., and Tatsumisago, M. (2008). Formation of $\mathrm{Li}+$ superionic crystals from the Li 2S-P2S5 melt-quenched glasses. J. Mater. Sci. 43, 1885-1889. doi: 10.1007/s10853-007-2421-2420

Hayashi, A., Muramatsu, H., Ohtomo, T., Hama, S., and Tatsumisago, M. (2013). Improvement of chemical stability of $\mathrm{Li}_{3} \mathrm{PS}_{4}$ glass electrolytes by adding $\mathrm{M}_{x} \mathrm{O}_{y}$ $(\mathrm{M}=\mathrm{Fe}, \mathrm{Zn}$, and $\mathrm{Bi})$ nanoparticles. J. Mater. Chem. A 1, 6320-6326. doi: $10.1039 / \mathrm{c} 3 \operatorname{ta} 10247 \mathrm{e}$

Heitmann, T., Hester, G., Mitra, S., Calloway, T., Tyagi, M. S., Miskowiec, A., et al. (2019). Probing Li ion dynamics in amorphous xLi 2 SO $4 \cdot(1-\mathrm{x}) \mathrm{LiPO} 3$ by quasielastic neutron scattering. Solid State Ionics 334, 95-98. doi: 10.1016/j.ssi. 2019.02.004

Herbert, E. G., Tenhaeff, W. E., Dudney, N. J., and Pharr, G. M. (2011). Mechanical characterization of LiPON films using nanoindentation. Thin Solid Films 520, 413-418. doi: 10.1016/j.tsf.2011.07.068

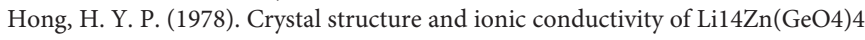
and other new Li+ superionic conductors. Mater. Res. Bull. 13, 117-124. doi: 10.1016/0025-5408(78)90075-90072

Hori, S., Suzuki, K., Hirayama, M., Kato, Y., and Kanno, R. (2016). Lithium superionic conductor Li $9.42 \mathrm{Si} 1.02$ P $2.1 \mathrm{~S} 9.96$ O 2.04 with Li $10 \mathrm{GeP}$ 2 S 12 -type structure in the Li 2 S-P 2 S 5 -SiO 2 pseudoternary system: synthesis, electrochemical properties, and structure-composition relationships. Front. Energy Res. 4:38. doi: 10.3389/fenrg.2016.00038

Hori, S., Suzuki, K., Hirayama, M., Kato, Y., Saito, T., Yonemura, M., et al. (2014). Synthesis, structure, and ionic conductivity of solid solution, Li 10+d M 1+d P 2 Àd S 12 (M 1/4 Si, Sn). Faraday Discuss 176, 83-94. doi: 10.1039/c4fd00143e

Hou, W., Guo, X., Shen, X., Amine, K., Yu, H., and Lu, J. (2018). Solid electrolytes and interfaces in all-solid-state sodium batteries: progress and perspective. Nano Energy 52, 279-291. doi: 10.1016/j.nanoen.2018.07.036

Huang, B., Yao, X., Huang, Z., Guan, Y., Jin, Y., and Xu, X. (2015). $\mathrm{Li}_{3} \mathrm{PO}_{4}$-doped $\mathrm{Li}_{7} \mathrm{P}_{3} \mathrm{~S}_{11}$ glass-ceramic electrolytes with enhanced lithium ion conductivities and application in all-solid-state batteries. J. Power Sources 284, 206-211. doi: 10.1016/j.jpowsour.2015.02.160

Hummel, R. (1985). Electronic Properties of Materials, 1st Edn. New York, NY: Springer-Verlag.

Ingram, M. D., Moynihan, C. T., and Lesikar, A. V. (1980). Ionic conductivity and the weak electrolyte theory of glass. J. Non. Cryst. Solids 3, 371-376. doi: 10.1016/0022-3093(80)90447-0

Inoue, T., and Mukai, K. (2017). Are all-solid-state lithium-ion batteries really safe?-verification by differential scanning calorimetry with an all-inclusive microcell. ACS Appl. Mater. Interfaces 9, 1507-1515. doi: 10.1021/acsami. $6 \mathrm{~b} 13224$

Jacke, S., Song, J., Cherkashinin, G., Dimesso, L., and Jaegermann, W. (2010). Investigation of the solid-state electrolyte/cathode $\mathrm{LiPON} / \mathrm{LiCoO} 2$ interface by photoelectron spectroscopy. Ionics 16, 769-775. doi: 10.1007/s11581-0100479-471

Jacke, S., Song, J., Dimesso, L., Brötz, J., Becker, D., and Jaegermann, W. (2011). Temperature dependent phosphorous oxynitride growth for all-solid-state batteries. J. Power Sources 196, 6911-6914. doi: 10.1016/j.jpowsour.2010.12.022

Janek, J., and Zeier, W. G. (2016). A solid future for battery development. Nat. Energy 1:16141. doi: 10.1038/nenergy.2016.141

Julien, C. M., Mauger, A., and Hussain, O. M. (2019). Sputtered LiCoO2 cathode materials for all-solid-state thin-film lithium microbatteries. Materials 12, 1-26. doi: $10.3390 / \mathrm{ma} 12172687$

Kamaya, N., Homma, K., Yamakawa, Y., Hirayama, M., Kanno, R., Yonemura, M., et al. (2011). A lithium superionic conductor. Nat. Mater. 10, 682-686. doi: $10.1038 /$ nmat3066

Kataoka, K., Nagata, H., and Akimoto, J. (2018). Lithium-ion conducting oxide single crystal as solid electrolyte for advanced lithium battery application. Sci. Rep. 8, 13-15. doi: 10.1038/s41598-018-27851-x

Keller, M., Varzi, A., and Passerini, S. (2018). Hybrid electrolytes for lithium metal batteries. J. Power Sources 392, 206-225. doi: 10.1016/j.jpowsour.2018.04.099

Kerman, K., Luntz, A., Viswanathan, V., Chiang, Y.-M., and Chen, Z. (2017). Review-practical challenges hindering the development of solid state Li ion batteries. J. Electrochem. Soc. 164, A1731-A1744. doi: 10.1149/2.1571707jes
Kim, J. G., Son, B., Mukherjee, S., Schuppert, N., Bates, A., Kwon, O., et al. (2015). A review of lithium and non-lithium based solid state batteries. J. Power Sources 282, 299-322. doi: 10.1016/j.jpowsour.2015.02.054

Koerver, R., Zhang, W., De Biasi, L., Schweidler, S., Kondrakov, A. O., Kolling, S., et al. (2018). Chemo-mechanical expansion of lithium electrode materials-on the route to mechanically optimized all-solid-state batteries. Energy Environ. Sci. 11, 2142-2158. doi: 10.1039/c8ee00907d

Kudu, ÖU., Famprikis, T., Fleutot, B., Braida, M. D., Le Mercier, T., Islam, M. S., et al. (2018). A review of structural properties and synthesis methods of solid electrolyte materials in the Li2S - P2S5 binary system. J. Power Sources 407, 31-43. doi: 10.1016/j.jpowsour.2018.10.037

Lacivita, V., Artrith, N., and Ceder, G. (2018a). Structural and Compositional Factors That Control the Li-Ion Conductivity in LiPON Electrolytes. Chem. Mater. 30, 7077-7090. doi: 10.1021/acs.chemmater.8b02812

Lacivita, V., Westover, A. S., Kercher, A., Phillip, N. D., Yang, G., Veith, G., et al. (2018b). Resolving the amorphous structure of lithium phosphorus oxynitride (Lipon). J. Am. Chem. Soc. 140, 11029-11038. doi: 10.1021/jacs.8b05192

Larcher, D., and Tarascon, J. M. (2015). Towards greener and more sustainable batteries for electrical energy storage. Nat. Chem. 7, 19-29. doi: 10.1038/nchem. 2085

Lau, J., DeBlock, R. H., Butts, D. M., Ashby, D. S., Choi, C. S., and Dunn, B. S. (2018). Sulfide Solid Electrolytes for Lithium Battery Applications. Adv. Energy Mater. 8, 1-24. doi: 10.1002/aenm.201800933

Le Van-Jodin, L., Ducroquet, F., Sabary, F., and Chevalier, I. (2013). Dielectric properties, conductivity and $\mathrm{Li}+$ ion motion in LiPON thin films. Solid State Ionics 253, 151-156. doi: 10.1016/j.ssi.2013.09.031

Li, D., Ma, Z., Xu, J., Li, Y., and Xie, K. (2014). High temperature property of allsolid-state thin film lithium battery using LiPON electrolyte. Mater. Lett. 134, 237-239. doi: 10.1016/j.matlet.2014.07.092

Li, J., Ma, C., Chi, M., Liang, C., and Dudney, N. J. (2015). Solid electrolyte: the key for high-voltage lithium batteries. Adv. Energy Mater. 5, 1-6. doi: 10.1002/ aenm.201401408

Lin, Z., Liu, T., Ai, X., and Liang, C. (2018). Aligning academia and industry for unified battery performance metrics. Nat. Commun. 9:5262. doi: 10.1038/ s41467-018-07599-7598

Liu, Z., Fu, W., Payzant, E. A., Yu, X., Wu, Z., Dudney, N. J., et al. (2013). Anomalous high ionic conductivity of nanoporous $\beta-\mathrm{Li}_{3} \mathrm{PS}_{4}$. J. Am. Chem. Soc. 135, 975-978. doi: 10.1021/ja3110895

Lu, P., Ding, F., Xu, Z., Liu, J., Liu, X., and Xu, Q. (2017). Study on $(100-\mathrm{x})\left(70 \mathrm{Li}_{2} \mathrm{~S}-30 \mathrm{P}_{2} \mathrm{~S}_{5}\right)-\mathrm{xLi}_{2} \mathrm{ZrO}_{3}$ glass-ceramic electrolyte for all-solid-state lithium-ion batteries. J. Power Sources 356, 163-171. doi: 10.1016/j.jpowsour. 2017.04.083

Luntz, A. C., Voss, J., and Reuter, K. (2015). Interfacial challenges in solid-state Li ion batteries. J. Phys. Chem. Lett. 6, 4599-4604. doi: 10.1021/acs.jpclett.5b02352

Luo, X., Lang, J., Lv, S., and Li, Z. (2018). High performance sandwich structured Si thin film anodes with LiPON coating. Front. Mater. Sci. 12:147-155. doi: 10.1007/s11706-018-0416-411

Lv, S., Li, M., Luo, X., Cheng, J., and Li, Z. (2020). High-voltage LiNi0.5Mn1.5O4 thin film cathodes stabilized by LiPON solid electrolyte coating to enhance cyclic stability and rate capability. J. Alloys Compd. 815:151636. doi: 10.1016/ j.jallcom.2019.07.348

Malugani, J. P., and Robert, G. (1979). Conductivite ionique dans les verres LiPO3LiX (X = I, Br, Cl). Mater. Res. Bull. 14, 1075-1081. doi: 10.1016/00255408(79)90075-90078

Mani, P. D., Saraf, S., Singh, V., Real-Robert, M., Vijayakumar, A., Duranceau, S. J., et al. (2016). Ionic conductivity of bias sputtered lithium phosphorus oxy-nitride thin films. Solid State Ionics 287, 48-59. doi: 10.1016/j.ssi.2016. 01.046

Manthiram, A., Yu, X., and Wang, S. (2017). Lithium battery chemistries enabled by solid-state electrolytes. Nat. Rev. Mater. 2, 1-16. doi: 10.1038/natrevmats. 2016.103

Martin, S. W. (1991). Ionic conduction in phosphate glasses. J. Am. Ceram. Soc. 74, 1767-1784. doi: 10.1111/j.1151-2916.1991.tb07788.x

Martin, S. W., Christensen, R., Olson, G., Kieffer, J., and Wang, W. (2019). New Interpretation of $\mathrm{Na}+-\mathrm{Ion}$ conduction in and the structures and properties of sodium borosilicate mixed glass former glasses. J. Phys. Chem. C 123, 5853-5870. doi: 10.1021/acs.jpcc.8b11735 
Mascaraque, N., Fierro, J. L. G., Durán, A., and Muñoz, F. (2013). An interpretation for the increase of ionic conductivity by nitrogen incorporation in LiPON oxynitride glasses. Solid State Ionics 233, 73-79. doi: 10.1016/j.ssi.2012.12.017

Mauro, J. C. (2011). Topological constraint theory of glass. Am. Ceram. Soc. Bull. 90, 31-37.

Mauro, J. C., Gupta, P. K., and Loucks, R. J. (2009a). Composition dependence of glass transition temperature and fragility. II. A topological model of alkali borate liquids. J. Chem. Phys. 130:234503. doi: 10.1063/1.3152432

Mauro, J. C., Yue, Y., Ellison, A. J., Gupta, P. K., and Allan, D. C. (2009b). Viscosity of glass-forming liquids. Proc. Natl. Acad. Sci. U.S.A. 106, 19780-19784. doi: 10.1073pnas.0911705106

Mercier, R., Malugani, J., Fahys, B., and Robert, G. (1981). Superionic conduction in Li2S-P2S5-LiI glasses. Solid State Ionics 5, 663-666.

Minami, K., Hayashi, A., Ujiie, S., and Tatsumisago, M. (2011a). Electrical and electrochemical properties of glass-ceramic electrolytes in the systems Li2SP2S5-P2S 3 and Li2S-P2S5-P2O 5. Solid State Ionics 192, 122-125. doi: 10.1016/ j.ssi.2010.06.018

Minami, K., Hayashi, A., Ujiie, S., and Tatsumisago, M. (2011b). NO-Electrical and electrochemical properties of glass-ceramic electrolytes in the systems Li2SP2S5-P2S 3 and Li2S-P2S5-P2O 5. Solid State Ionics 192, 122-125. doi: 10.1016/ j.ssi.2010.06.018

Mizuno, F., Hayashi, A., Tadanaga, K., and Tatsumisago, M. (2006). High lithium ion conducting glass-ceramics in the system Li2S-P2S5. Solid State Ionics 177, 2721-2725. doi: 10.1016/j.ssi.2006.04.017

Mo, S., Lu, P., Ding, F., Xu, Z., Liu, J., Liu, X., et al. (2016). High-temperature performance of all-solid-state battery assembled with 95(0.7Li2S-0.3P2S5)5Li3PO4 glass electrolyte. Solid State Ionics 296, 37-41. doi: 10.1016/j.ssi.2016. 09.002

Mori, K., Ichida, T., Iwase, K., Otomo, T., Kohara, S., Arai, H., et al. (2013). Visualization of conduction pathways in lithium superionic conductors: Li2SP2S5 glasses and Li7P 3S11 glass-ceramic. Chem. Phys. Lett. 584, 113-118. doi: $10.1016 /$ j.cplett.2013.08.016

Motoyama, M., Ejiri, M., and Iriyama, Y. (2015). Modeling the nucleation and growth of $\mathrm{Li}$ at metal current collector/LiPON interfaces. J. Electrochem. Soc. 162, A7067-A7071. doi: 10.1149/2.0051513jes

Motoyama, M., Ejiri, M., Yamamoto, T., Iriyama, Y., doped, and Li, O. (2018). In Situ Scanning Electron Microscope Observations of Li Plating/Stripping Reactions with Pt Current Collectors on LiPON Electrolyte Along with successful developments on lithium superionic conductors in the last couple of decades (e. J. Electrochem. Soc. 165, 1338-1347. doi: 10.1149/2.0411807jes

Muñoz, F. (2012). Comments on the structure of LiPON thin-film solid electrolytes. J. Power Sources 198, 432-433. doi: 10.1016/j.jpowsour.2011.09.009

Muramatsu, H., Hayashi, A., Ohtomo, T., Hama, S., and Tatsumisago, M. (2011). Structural change of Li2S-P2S5 sulfide solid electrolytes in the atmosphere. Solid State Ionics 182, 116-119. doi: 10.1016/j.ssi.2010.10.013

Murugan, R., Thangadurai, V., and Weppner, W. (2007). Fast lithium ion conduction in garnet-type Li7La 3Zr2O12. Angew. Chemie Int. Ed. 46, 77787781. doi: 10.1002/anie.200701144

Nakamura, T., Amezawa, K., Kulisch, J., Zeier, W. G., and Janek, J. (2019). Guidelines for All-Solid-State Battery Design and Electrode Buffer Layers Based on Chemical Potential Profile Calculation. ACS Appl. Mater. Interfaces 11, 19968-19976. doi: 10.1021/acsami.9b03053

Nie, K., Hong, Y., Qiu, J., Li, Q., Yu, X., Li, H., et al. (2018). Interfaces between cathode and electrolyte in solid state lithium batteries: challenges and perspectives. Front. Chem. 6:616. doi: 10.3389/fchem.2018.00616

Nimisha, C. S., Rao, G. M., Munichandraiah, N., Natarajan, G., and Cameron, D. C. (2011). Chemical and microstructural modifications in LiPON thin films exposed to atmospheric humidity. Solid State Ionics 185, 47-51. doi: 10.1016/j. ssi.2011.01.001

Notten, P. H. L., Roozeboom, F., Niessen, R. A. H., and Baggetto, L. (2007). 3D integrated all-solid-state rechargeable batteries. Adv. Mater. 19, 4564-4567. doi: 10.1002/adma.200702398

Nowak, S., Berkemeier, F., and Schmitz, G. (2015). Ultra-thin LiPON films Fundamental properties and application in solid state thin film model batteries. J. Power Sources 275, 144-150. doi: 10.1016/j.jpowsour.2014.10.202

Ohara, K., Mitsui, A., Mori, M., Onodera, Y., Shiotani, S., Koyama, Y., et al. (2016). Structural and electronic features of binary Li2S-P2S5 glasses. Sci. Rep. 6:21302. doi: $10.1038 /$ srep21302
Ohtomo, T., Hayashi, A., Tatsumisago, M., and Kawamoto, K. (2013a). Characteristics of the Li2O-Li2S-P2S 5 glasses synthesized by the two-step mechanical milling. J. Non. Cryst. Solids 364, 57-61. doi: 10.1016/j.jnoncrysol. 2012.12.044

Ohtomo, T., Hayashi, A., Tatsumisago, M., and Kawamoto, K. (2013b). Glass Electrolytes with High Ion Conductivity and High Chemical Stability in the System LiI-Li2O-Li2S-P2S5. Electrochemistry 81, 428-431. doi: 10.5796/ electrochemistry. 81.428

Ohtomo, T., Hayashi, A., Tatsumisago, M., Tsuchida, Y., Hama, S., and Kawamoto, K. (2013c). All-solid-state lithium secondary batteries using the 75Li 2S-25P2S5 glass and the 70Li 2S.30P2S5 glass-ceramic as solid electrolytes. J. Power Sources 233, 231-235. doi: 10.1016/j.jpowsour.2013.01.090

Omata, T., Yamaguchi, T., Tsukuda, S., Ishiyama, T., Nishii, J., Yamashita, T., et al. (2019). Proton transport properties of proton-conducting phosphate glasses at their glass transition temperatures. Phys. Chem. Chem. Phys. 21, 10744-10749. doi: $10.1039 / \mathrm{c} 9 \mathrm{cp} 01502 \mathrm{~g}$

Onodera, Y., Mori, K., Otomo, T., Araib, H., Uchimoto, Y., Ogumi, Z., et al. (2013). Structural origin of ionic conductivity for Li 7 P 3 S 11 metastable crystal by neutron and X-ray diffraction Related content. J. Phys. Conf. Ser. 502:012021. doi: 10.1088/1742-6596/502/1/012021

Onodera, Y., Mori, K., Otomo, T., Sugiyama, M., and Fukunaga, T. (2012). Structural Evidence for High Ionic Conductivity of Li 7 P 3 S 11 Metastable Crystal. J. Phys. Soc. Japan 81:044802. doi: 10.1143/JPSJ.81.044802

Park, M., Jung, H. G., Jung, W. D., Cho, S. Y., Yun, B. N., Lee, Y. S., et al. (2017). Chemically evolved composite lithium-ion conductors with lithium thiophosphates and nickel sulfides. ACS Energy Lett. 2, 1740-1745. doi: 10.1021/ acsenergylett.7b00497

Pervez, S. A., Cambaz, M. A., Thangadurai, V., and Fichtner, M. (2019). Interface in solid-state Lithium battery: challenges, progress, and outlook. ACS Appl. Mater. Interfaces 11, 22029-22050. doi: 10.1021/acsami.9b02675

Pichonat, T., Lethien, C., Tiercelin, N., Godey, S., Pichonat, E., Roussel, P., et al. (2010). Further studies on the lithium phosphorus oxynitride solid electrolyte. Mater. Chem. Phys. 123, 231-235. doi: 10.1016/j.matchemphys.2010. 04.001

Porz, L., Swamy, T., Sheldon, B. W., Rettenwander, D., Frömling, T., Thaman, H. L., et al. (2017). Mechanism of Lithium Metal Penetration through Inorganic Solid Electrolytes. Adv. Energy Mater. 7, 1-12. doi: 10.1002/aenm.201701003

Put, B., Mees, M. J., Hornsveld, N., Hollevoet, S., Sepúlveda, A., Vereecken, P. M., et al. (2019). Plasma-Assisted ALD of LiPO(N) for Solid State Batteries. J. Electrochem. Soc. 166, 1239-1242. doi: 10.1149/2.1191906jes

Put, B., Vereecken, P. M., Meersschaut, J., Sepúlveda, A., and Stesmans, A. (2016). Electrical Characterization of Ultrathin RF-Sputtered LiPON Layers for Nanoscale Batteries. ACS Appl. Mater. Interfaces 8, 7060-7069. doi: 10.1021/ acsami.5b 12500

Put, B., Vereecken, P. M., and Stesmans, A. (2018). On the chemistry and electrochemistry of LiPON breakdown. J. Mater. Chem. A 6, 4848-4859. doi: $10.1039 / \mathrm{c} 7 \mathrm{ta} 07928 \mathrm{a}$

Ramstrom, O. (2019). Scientific Background on the Nobel Prize in Chemistry 2019. Stockholm: The Royal Swedish Academy Of Sciences.

Ravaine, D. (1980). Glasses as solid electrolytes. J. Non. Cryst. Solids 38-39, 353-358. doi: 10.1016/0022-3093(80)90444-90445

Ravaine, D., and Souquet, J. L. (1977). A thermodynamic approach to ionic conductivity in oxide glasses; 1 correlation of the ionic conductivity with the chemical potential of alkali oxide in oxide. Phys. Chem. Glas. 19:115.

Reyes Jiménez, A., Nölle, R., Wagner, R., Hüsker, J., Kolek, M., Schmuch, R., et al. (2018). A step towards understanding the beneficial influence of a LIPON-based artificial SEI on silicon thin film anodes in lithium-ion batteries. Nanoscale 10, 2128-2137. doi: 10.1039/c7nr06568j

Ribeiro, J. F., Sousa, R., Carmo, J. P., Gonçalves, L. M., Silva, M. F., Silva, M. M., et al. (2012). Enhanced solid-state electrolytes made of lithium phosphorous oxynitride films. Thin Solid Films 522, 85-89. doi: 10.1016/j.tsf.2012. 09.007

Richards, W. D., Miara, L. J., Wang, Y., Kim, J. C., and Ceder, G. (2016). Interface Stability in Solid-State Batteries. Chem. Mater. 28, doi: 10.1021/acs.chemmater. 5 b0 4082

Rodrigues, A. C. M., Nascimento, M. L. F., Bragatto, C. B., and Souquet, J. L. (2011). Charge carrier mobility and concentration as a function of composition in AgPO 3-AgI glasses. J. Chem. Phys. 135:234504. doi: 10.1063/1.3666835 
Saruwatari, H., Kuboki, T., Kishi, T., Mikoshiba, S., and Takami, N. (2010). Imidazolium ionic liquids containing $\mathrm{LiBOB}$ electrolyte for lithium battery. J. Power Sources 195, 1495-1499. doi: 10.1016/j.jpowsour.2009.08.081

Schwöbel, A., Hausbrand, R., and Jaegermann, W. (2015). Interface reactions between LiPON and lithium studied by in-situ X-ray photoemission. Solid State Ionics 273, 51-54. doi: 10.1016/j.ssi.2014.10.017

Seino, Y., Nakagawa, M., Senga, M., Higuchi, H., Takada, K., and Sasaki, T. (2015). Analysis of the structure and degree of crystallisation of 70Li 2 S-30P 2 S 5 glass ceramic. J. Mater. Chem. A 3, 2756-2761. doi: 10.1039/c4ta04332d

Sepúlveda, A., Criscuolo, F., Put, B., and Vereecken, P. M. (2019). Effect of high temperature LiPON electrolyte in all solid state batteries. Solid State Ionics 337, 24-32. doi: 10.1016/j.ssi.2019.03.023

Shin, B. R., Nam, Y. J., Oh, D. Y., Kim, D. H., Kim, J. W., and Jung, Y. S. (2014). Comparative study of TiS2/Li-In all-solid-state lithium batteries using glass-ceramic Li3PS4and Li10GeP2S12 solid electrolytes. Electrochim. Acta 146, 395-402. doi: 10.1016/j.electacta.2014.08.139

Shoji, M., Cheng, E. J., Kimura, T., and Kanamura, K. (2019). Recent progress for all solid state battery using sulfide and oxide solid electrolytes. J. Phys. D. Appl. Phys. 52, doi: 10.1088/1361-6463/aaf7e2

Sicolo, S., and Albe, K. (2016). First-principles calculations on structure and properties of amorphous Li5P4O8N3 (LiPON). J. Power Sources 331, 382-390. doi: 10.1016/j.jpowsour.2016.09.059

Sicolo, S., Fingerle, M., Hausbrand, R., and Albe, K. (2017). Interfacial instability of amorphous LiPON against lithium: a combined Density Functional Theory and spectroscopic study. J. Power Sources 354, 124-133. doi: 10.1016/j.jpowsour. 2017.04.005

Smedskjaer, M. M., Mauro, J. C., Sen, S., and Yue, Y. (2010). Quantitative design of glassy materials using temperature-dependent constraint theory. Chem. Mater. 22, 5358-5365. doi: 10.1021/cm1016799

Smedskjaer, M. M., Zheng, Q., Mauro, J. C., Potuzak, M., Mørup, S., and Yue, Y. (2011). Sodium diffusion in boroaluminosilicate glasses. J. Non. Cryst. Solids 357, 3744-3750. doi: 10.1016/j.jnoncrysol.2011.07.008

Song, J., Jacke, S., Becker, D., Hausbrand, R., and Jaegermann, W. (2011a). Stabilization of thin film $\mathrm{LiCoO} 2$ electrode by LiPON coating. Electrochem. Solid-State Lett. 14, 2-5. doi: 10.1149/1.3511772

Song, J., Jacke, S., Cherkashinin, G., Schmid, S., Dong, Q., Hausbrand, R., et al. (2011b). Valence band offsets of LiPONLiCoO 2 hetero-interfaces determined by X-ray photoelectron spectroscopy. Electrochem. Solid-State Lett. 14, 189-191. doi: 10.1149/2.006112esl

Song, S. W., Choi, H., Park, H. Y., Park, G. B., Lee, K. C., and Lee, H. J. (2010). High rate-induced structural changes in thin-film lithium batteries on flexible substrate. J. Power Sources 195, 8275-8279. doi: 10.1016/j.jpowsour.2010. 06.113

Song, S. W., Lee, K. C., and Park, H. Y. (2016). High-performance flexible allsolid-state microbatteries based on solid electrolyte of lithium boron oxynitride. J. Power Sources 328, 311-317. doi: 10.1016/j.jpowsour.2016.07.114

Souquet, J. L., Nascimento, M. L. F., and Rodrigues, A. C. M. (2010). Charge carrier concentration and mobility in alkali silicates. J. Chem. Phys. 132:034704. doi: 10.1063/1.3271154

Souquet, J. L., and Perera, W. G. (1990). Thermodynamics applied to ionic transport in glasses. Solid State Ionics 4, 595-604. doi: 10.1016/0167-2738(90) 90078-90076

Spannenberger, S., Miß, V., Klotz, E., Kettner, J., Cronau, M., Ramanayagam, A., et al. (2019). Annealing-induced vacancy formation enables extraordinarily high $\mathrm{Li}+$ ion conductivity in the amorphous electrolyte $0.33 \mathrm{LiI}+0.67 \mathrm{Li} 3 \mathrm{PS} 4$. Solid State Ionics 341:115040. doi: 10.1016/j.ssi.2019.115040

Stallworth, P. E., Vereda, F., Greenbaum, S. G., Haas, T. E., Zerigian, P., and Goldner, R. B. (2005). Solid-state NMR studies of lithium phosphorus oxynitride films prepared by nitrogen ion beam-assisted deposition. J. Electrochem. Soc. 152, 516-522. doi: 10.1149/1.1856922

Su, Y., Falgenhauer, J., Polity, A., Leichtweiß, T., Kronenberger, A., Obel, J., et al. (2015). LiPON thin films with high nitrogen content for application in lithium batteries and electrochromic devices prepared by RF magnetron sputtering. Solid State Ionics 282, 63-69. doi: 10.1016/j.ssi.2015.09.022

Suyama, M., Kato, A., Sakuda, A., Hayashi, A., and Tatsumisago, M. (2018). Lithium dissolution/deposition behavior with Li3PS4-LiI electrolyte for allsolid-state batteries operating at high temperatures. Electrochim. Acta 286, 158-162. doi: 10.1016/j.electacta.2018.07.227
Swenson, J., McGreevy, R. L., Börjesson, L., and Wicks, J. D. (1998). Relations between structure and conductivity in fast ion conducting glasses. Solid State Ionics 105, 55-65. doi: 10.1016/s0167-2738(97)00449-9

Tan, D. H. S., Banerjee, A., Chen, Z., and Meng, Y. S. (2020). From nanoscale interface characterization to sustainable energy storage using all-solid-state batteries. Nat. Nanotechnol. 15, 170-180. doi: 10.1038/s41565-020-0657-x

Tarascon, J. M., and Armand, M. (2001). Issues and Challenges facing rechargeable lithium batteries. Nature 414, 359-367. doi: 10.1016/0167-2738(86)9017690171

Tatsumisago, M., and Hayashi, A. (2014). Sulfide glass-ceramic electrolytes for all-solid-state lithium and sodium batteries. Int. J. Appl. Glas. Sci. 5, 226-235. doi: 10.1111/ijag.12084

Thai, K., and Lee, E. (2017). Effects of mechanical strain on ionic conductivity in the interface between LiPON and Ni-Mn spinel. J. Electrochem. Soc. 164, A594-A599. doi: 10.1149/2.0661704jes

Tintignac, S., Baddour-Hadjean, R., Pereira-Ramos, J. P., and Salot, R. (2014). High rate bias sputtered $\mathrm{LiCoO} 2$ thin films as positive electrode for all-solid-state lithium microbatteries. Electrochim. Acta 146, 472-476. doi: 10.1016/j.electacta. 2014.09.084

Tsai, C. L., Roddatis, V., Chandran, C. V., Ma, Q., Uhlenbruck, S., Bram, M., et al. (2016). Li7La3Zr2O12 interface modification for li dendrite prevention. ACS Appl. Mater. Interfaces 8, 10617-10626. doi: 10.1021/acsami. 6b00831

Tsukasaki, H., Mori, Y., Otoyama, M., Yubuchi, S., Asano, T., Tanaka, Y., et al. (2018). Crystallization behavior of the Li 2 S-P 2 S 5 glass electrolyte in the LiNi 1/3 Mn 1/3 Co 1/3 O 2 positive electrode layer. Sci. Rep. 2:6214. doi: 10.1038/s41598-018-24524-24527

Tuller, H. L., Button, D. P., and Uhlmann, D. R. (1980). Fast ion transport in oxide glasses. J. Non. Cryst. Solids 40, 93-118. doi: 10.1016/0022-3093(80)9009690094

Uddin, M. J., and Cho, S. J. (2018). Reassessing the bulk ionic conductivity of solidstate electrolytes. Sustain. Energy Fuels 2, 1458-1462. doi: 10.1039/c8se00139a

Ujiie, S., Hayashi, A., and Tatsumisago, M. (2012). Structure, ionic conductivity and electrochemical stability of $\mathrm{Li}_{2} \mathrm{~S}_{-} \mathrm{P}_{2} \mathrm{~S}_{5}$-LiI glass and glass-ceramic electrolytes. Solid State Ionics 211, 42-45. doi: 10.1016/j.ssi.2012.01.017

Uma, T., and Nogami, M. (2008). Proton-conducting glass electrolyte. Anal. Chem. 80, 506-508. doi: 10.1021/ac0706630

Varshneya, K., and Mauro, J. C. (2019). Fundamentals of Inorganic Glasses, 3rd Edn. Amsterdam: Elsevier.

Vieira, E. M. F., Ribeiro, J. F., Silva, M. M., Barradas, N. P., Alves, E., Alves, A., et al. (2016). Electrical insulation properties of RF-sputtered LiPON layers towards electrochemical stability of lithium batteries. J. Phys. D. Appl. Phys. 49:485301. doi: 10.1088/0022-3727/49/48/485301

Von Alpen, U., and Bell, M. F. (1981). Compositional Dependence of the Electrochemical and Structural Parameters in the NASICON System (Na1+xZr2SixP3-xO12). Solid State Ionics 3, 215-218. doi: 10.1016/01672738(81)90085-0

Wang, W., Yue, X., Meng, J., Wang, J., Wang, X., Chen, H., et al. (2019). Lithium phosphorus oxynitride as an efficient protective layer on lithium metal anodes for advanced lithium-sulfur batteries. Energy Storage Mater. 18, 414-422. doi: 10.1016/j.ensm.2018.08.010

Wang, Z., Santhanagopalan, D., Zhang, W., Wang, F., Xin, H. L., He, K., et al. (2016). In situ STEM-EELS observation of nanoscale interfacial phenomena in all-solid-state batteries. Nano Lett. 16, 3760-3767. doi: 10.1021/acs.nanolett. $6 \mathrm{~b} 01119$

Wei, K., Zhao, Y., Cui, Y., Wang, J., Cui, Y., Zhu, R., et al. (2018). Lithium phosphorous oxynitride (LiPON) coated NiFe 2 O 4 anode material with enhanced electrochemical performance for lithium ion batteries. J. Alloys Compd. 769, 110-119. doi: 10.1016/j.jallcom.2018.07.153

Weiss, M., Seidlhofer, B. K., Geiß, M., Geis, C., Busche, M. R., Becker, M., et al. (2019). Unraveling the Formation Mechanism of Solid-Liquid Electrolyte Interphases on LiPON Thin Films. ACS Appl. Mater. Interfaces 11, 9539-9547. doi: 10.1021/acsami.8b19973

Welch, R. S., Wilkinson, C. J., Mauro, J. C., and Bragatto, C. B. (2019). Charge carrier mobility of alkali silicate glasses calculated by molecular dynamics. Front. Mater. 6:121. doi: 10.3389/fmats.2019.00121

West, W. C., Hood, Z. D., Adhikari, S. P., Liang, C., Lachgar, A., Motoyama, M., et al. (2016). Reduction of charge-transfer resistance at the solid 
electrolyte - Electrode interface by pulsed laser deposition of films from a crystalline Li2PO2N source. J. Power Sources 312, 116-122. doi: 10.1016/j. jpowsour.2016.02.034

Westover, A. S., Dudney, N. J., Sacci, R. L., and Kalnaus, S. (2019). Deposition and Confinement of Li Metal along an Artificial Lipon-Lipon Interface. ACS Energy Lett. 4, 651-655. doi: 10.1021/acsenergylett.8b02542

Wilkinson, C. J., Doss, K., Palmer, G., and Mauro, J. C. (2019a). The relativistic glass transition: a thought experiment. J. Non-Crystalline Solids X 2:100018. doi: 10.1016/j.nocx.2019.100018

Wilkinson, C. J., Zheng, Q., Huang, L., and Mauro, J. C. (2019b). Topological constraint model for the elasticity of glass-forming systems. J. Non-Crystalline Solids X 2, 100019. doi: 10.1016/j.nocx.2019.100019

Wilkinson, C. J., Doss, K., Cassar, D. R., Welch, R. S., Bragatto, C. B., and Mauro, J. C. (2020). Predicting ionic diffusion in glass from its relaxation behavior. J. Phys. Chem. B 124, 1099-1103. doi: 10.1021/acs.jpcb.9b10645

Xiao, B., Wang, K., Xu, G. L., Song, J., Chen, Z., Amine, K., et al. (2019). Revealing the atomic origin of heterogeneous Li-ion diffusion by probing Na. Adv. Mater. 31, 1-9. doi: 10.1002/adma.201805889

Xiao, D. L., Tong, J., Feng, Y., Zhong, G. H., Li, W. J., and Yang, C. L. (2018). Improved performance of all-solid-state lithium batteries using LiPON electrolyte prepared with Li-rich sputtering target. Solid State Ionics 324, $202-$ 206. doi: 10.1016/j.ssi.2018.07.011

Xu, R. C., Xia, X. H., Wang, X. L., Xia, Y., and Tu, J. P. (2017). Tailored Li2S-P2S5 glass-ceramic electrolyte by MoS2 doping, possessing high ionic conductivity for all-solid-state lithium-sulfur batteries. J. Mater. Chem. A 5, 2829-2834. doi: 10.1039/c6ta10142a

Xu, R. C., Xia, X. H., Zhang, S. Z., Xie, D., Wang, X. L., and Tu, J. P. (2018). Interfacial challenges and progress for inorganic all-solid-state lithium batteries. Electrochim. Acta 284, 177-187. doi: 10.1016/j.electacta.2018.07.191

Yada, C., Ohmori, A., Ide, K., Yamasaki, H., Kato, T., Saito, T., et al. (2014). Dielectric modification of $5 \mathrm{~V}$-class cathodes for high-voltage all-solid-state lithium batteries. Adv. Energy Mater. 4, 1-5. doi: 10.1002/aenm.201301416

Yamaguchi, T., Tsukuda, S., Ishiyama, T., Nishii, J., Yamashita, T., Kawazoe, H., et al. (2018). Proton-conducting phosphate glass and its melt exhibiting high electrical conductivity at intermediate temperatures. J. Mater. Chem. A 6, 23628-23637. doi: 10.1039/C8TA08162J

Yamauchi, A., Sakuda, A., Hayashi, A., and Tatsumisago, M. (2013). Preparation and ionic conductivities of $(100-\mathrm{X})(0.75 \mathrm{Li} 2 \mathrm{~S} \cdot 0.25 \mathrm{P} 2 \mathrm{~S} 5) \cdot \mathrm{xLiBH} 4$ glass electrolytes. J. Power Sources 244, 707-710. doi: 10.1016/j.jpowsour.2012. 12.001

Yersak, T. A., Salvador, J. R., Pieczonka, N. P., Cai, M., and Li, G. (2019). Dense, Melt Cast Sulfide Glass Electrolyte Separators for Li Metal Batteries. J. Electrochem. Soc. 166, 1535-1542. doi: 10.1149/2.0841908jes

Yim, H., Yu, S. H., Baek, S. H., Sung, Y. E., and Choi, J. W. (2020). Directly integrated all-solid-state flexible lithium batteries on polymer substrate. J. Power Sources 455, 227978. doi: 10.1016/j.jpowsour.2020.227978
Yoon, Y., Park, C., Kim, J., and Shin, D. (2012). Characterization of lithium borophosphate glass thin film electrolytes deposited by RF-magnetron sputtering for micro-batteries. Solid State Ionics 225, 636-640. doi: 10.1016/j. ssi.2012.05.008

Yu, X., Bates, J. B., Jellison, G. E., and Hart, F. X. (1997). A stable thin-film lithium electrolyte: Lithium phosphorus oxynitride. J. Electrochem. Soc. 144, 524-532. doi: 10.1149/1.1837443

Zhang, Y., Chen, K., Shen, Y., Lin, Y., and Nan, C. W. (2017). Synergistic effect of processing and composition $\mathrm{x}$ on conductivity of $\mathrm{xLi}_{2} \mathrm{~S}-(100-\mathrm{x}) \mathrm{P}_{2} \mathrm{~S}_{5}$ electrolytes. Solid State Ionics 305, 1-6. doi: 10.1016/j.ssi.2017.03.024

Zhang, N., Ding, F., Yu, S., Zhu, K., Li, H., Zhang, W., et al. (2019). Novel Research Approach Combined with Dielectric Spectrum Testing for Dual-Doped Li 7 P 3 S 11 Glass-Ceramic Electrolytes. ACS Appl. Mater. Interfaces 11:8. doi: 10.1021/acsami.9b08218

Zhang, Z., Shao, Y., Lotsch, B., Hu, Y.-S., Li, H., Rgen Janek, J., et al. (2018). New horizons for inorganic solid state ion conductors. Energy Environ. Sci 11:1945. doi: 10.1039/c8ee01053f

Zhao, R., Kmiec, S., Hu, G., and Martin, S. W. (2020). Lithium Thiosilicophosphate Glassy Solid Electrolytes Synthesized by High-Energy Ball-Milling and Meltquenching: improved suppression of lithium dendrite growth by Si Doping. ACS Appl. Mater. Interfaces 12, 2327-2337. doi: 10.1021/acsami.9b16792

Zheng, F., Kotobuki, M., Song, S., Lai, M. O., and Lu, L. (2018). Review on solid electrolytes for all-solid-state lithium-ion batteries. J. Power Sources 389, 198-213. doi: 10.1016/j.jpowsour.2018.04.022

Zheng, Q., Mauro, J. C., Ellison, A. J., Potuzak, M., and Yue, Y. (2011). Universality of the high-temperature viscosity limit of silicate liquids. Phys. Rev. B Condens. Matter Mater. Phys. 83, 13-15. doi: 10.1103/PhysRevB.83.212202

Zhou, B., Guo, L., Zhang, Y., Wang, J., Ma, L., Zhang, W. H., et al. (2017). A High-Performance Li-O2 Battery with a Strongly Solvating Hexamethylphosphoramide Electrolyte and a LiPON-Protected Lithium Anode. Adv. Mater. 29, 2-7. doi: 10.1002/adma.201701568

Zhu, Y., He, X., and Mo, Y. (2015). Origin of outstanding stability in the lithium solid electrolyte materials: insights from thermodynamic analyses based on first-principles calculations. ACS Appl. Mater. Interfaces 7, 23685-23693. doi: 10.1021/acsami.5b07517

Conflict of Interest: The authors declare that the research was conducted in the absence of any commercial or financial relationships that could be construed as a potential conflict of interest.

Copyright (c) 2020 Grady, Wilkinson, Randall and Mauro. This is an open-access article distributed under the terms of the Creative Commons Attribution License (CC BY). The use, distribution or reproduction in other forums is permitted, provided the original author(s) and the copyright owner(s) are credited and that the original publication in this journal is cited, in accordance with accepted academic practice. No use, distribution or reproduction is permitted which does not comply with these terms. 